\title{
Composição demográfica domiciliar e dinâmica do uso do solo em Machadinho d'Oeste, Rondônia: evidências baseadas nos estágios iniciais da fronteira
}

\author{
Gilvan Ramalho Guedes* \\ Alisson Barbieri** \\ Reinaldo Santos ${ }^{\star \star \star}$ \\ Vanessa Ferreira****
}

\begin{abstract}
Vários estudos sugerem a importância da mudança na composição demográfica domiciliar sobre a demanda e o uso da terra em fronteiras agrícolas. A maioria desses estudos, no entanto, analisa essa relação em estágios mais avançados do desenvolvimento das fronteiras, produzindo evidências conflitantes sobre o papel dos determinantes populacionais. Este artigo examina os efeitos da composição demográfica domiciliar (ciclo de vida domiciliar) e do tempo na propriedade (ciclo no lote) sobre a dinâmica de uso do solo em pequenas propriedades rurais em Machadinho d'Oeste, Rondônia. Foram utilizados dados de uma pesquisa censitária sobre os colonos do projeto de assentamento original, para 1987 e 1995. A relação entre os ciclos e as classes de uso do solo foi analisada por meio de modelos de regressão Beta e de Dirichlet. Observou-se uma relação consistente entre oferta de trabalho familiar e estoque desmatado no nível da propriedade rural. 0 tempo na propriedade também se mostrou associado ao desmatamento, embora seu efeito não linear sugira a experimentação com o ambiente biofísico local. Sugere-se que os efeitos do ciclo de vida e no lote se autodeterminam nos estágios iniciais da fronteira, indicando a importância dos efeitos da composição demográfica sobre a dinâmica de uso da terra.
\end{abstract}

Palavras-chave: Machadinho d'Oeste. Amazônia brasileira. Fronteira. Ciclo de vida domiciliar. Ciclo de vida do lote. Desmatamento.

\footnotetext{
* Centro de Desenvolvimento e Planejamento Regional (Cedeplar), Universidade Federal de Minas Gerais (UFMG), Belo Horizonte-MG, Brasil (grguedes@cedeplar.ufmg.br).

${ }^{\star \star}$ Universidade Federal de Minas Gerais (UFMG), Belo Horizonte-MG, Brasil (barbieri@cedeplar.ufmg.br).

*** Universidade Federal de Minas Gerais (UFMG), Belo Horizonte-MG, Brasil (reinaldosantos80@gmail.com).

${ }^{\star \star \star \star}$ Universidade Federal de Minas Gerais (UFMG), Belo Horizonte-MG, Brasil (va.cafes@gmail.com).
} 


\section{Introdução}

O campo teórico sobre demografia e meio ambiente cresceu muito nos últimos anos, sobretudo em decorrência do agravamento dos problemas ambientais globais e locais (PAN; CARR, 2016; BHATTI et al., 2017). Essas mudanças ambientais têm sido atribuídas a diversos fatores antrópicos, incluindo a mercantilização das fronteiras agrícolas (CALDAS et al., 2007), a expansão da infraestrutura predominantemente voltada para construção de estradas (PFAFF et al., 2009), os sistemas de uso do solo intensivos no fator terra (WALKER et al., 2000; BROWDER et al., 2004) e a urbanização não planejada (MARTINE, 2007).

A discussão sobre impactos ambientais antrópicos na Amazônia tem sido foco recorrente desse debate, dada a relevância da floresta Amazônica para o equilíbrio ecossistêmico planetário. Simulações da dinâmica da cobertura da terra em função do avanço das forças antrópicas sugerem que as taxas de desmatamento históricas praticadas na região foram suficientemente altas a ponto de reduzir a cobertura original pela metade (LAURANCE et al., 2005; SOARES-FILHO et al., 2006; NEPSTAD et al., 2008). Não somente o desmatamento tem sido uma ameaça para a Amazônia, mas também a degradação do bioma, ou seja, a piora da qualidade da cobertura florestal, de sua biodiversidade e do seu potencial endógeno de recuperação. Hayashi et al. (2011) estimam que o nível de degradação vegetal tenha crescido $35 \%$ em anos recentes. A abertura de novos assentamentos (PASQUIS et al., 2005) e a expansão do agronegócio (MORTON et al., 2006) podem representar uma pressão adicional nos próximos anos ao reorganizar as atividades agrícolas em bases mais intensivas em capital (RICHARDS; VANWEY, 2015), contribuindo para o deslocamento de pequenos agricultores para terras marginais (HUNTER; NAWROTZKI, 2016).

0 desmatamento ainda é o maior problema ambiental da Amazônia. No entanto, a maior parte dos estudos que lidam com a análise da cobertura florestal na região tem utilizado uma escala agregada (FERNSIDE, 1993; WOOD; SKOLE, 1998; PFAFF, 1999; LAURENCE et al., 2002; PERZ et al., 2005; BARBIERI, 2007; GUTIERREZ-VELEZ; DEFRIES, 2013). Inspirados nos modelos Ipat (Impacto = Progresso + Afluência + Tecnologia), vários trabalhos procuraram entender como a dinâmica populacional na região poderia estar associada à dinâmica da cobertura vegetal (PERZ, 2001, 2002). A grande heterogeneidade nas características dos sistemas de uso do solo e na relação terra/trabalho é uma das principais razões pelas quais esses estudos encontraram evidências fracas da relação entre população e desmatamento no contexto amazônico (GUEDES et al., 2011; VANWEY et al., 2007; BARBIERI, 2007; CARR et al., 2005).

Nos últimos anos, os avanços na disponibilidade de informação com maior escala de resolução e novas pesquisas amostrais em áreas de assentamento permitiram que a análise da relação entre dinâmica demográfica e ambiental nas fronteiras amazônicas priorizasse a abordagem micro, ou seja, a análise no nível das famílias (CORTES; D’ANTONA, 2014; GARDNER et al., 2013; GUEDES et al., 2017; D’ANTONA et al., 2006, 2007, 2008, 2011; PAN et al., 2004; BARBIERI, 2007). Sob essa perspectiva analítica, o desmatamento está 
relacionado às praticas agropastoris adotadas pelos colonos (famílias), embora haja explícito reconhecimento da influência de questões estruturais sobre as decisões desses colonos (WALKER et al., 2000; SIMMONS et al., 2007; BRONDIZIO, 2008; SCHMINK; WOOD, 2012).

Inspirado em estudos similares desenvolvidos no contexto amazônico (BARBIERI et al., 2005; VANWEY et al., 2007; VANWEY; VITHAYATHIL, 2013; LOMBARDI et al., 2015; GUEDES et al., 2017), este trabalho analisa como a composição demográfica e o tempo de residência das famílias de pequenos agricultores se relacionam com a intensidade observada do desmatamento em assentamentos agrícolas na Amazônia. Para tanto, foram utilizados dados sobre os colonos do Projeto de Assentamento Machadinho d'Oeste, no estado de Rondônia. Diferentemente de vários estudos que fizeram esse tipo de análise em fronteiras já consolidadas (BARBIERI et al., 2005; DE SHERBININ et al., 2008; GRAY et al., 2008; VANWEY et al., 2007; LUDEWIGS et al., 2009; CABRERA et al., 2012; SANTOS et al., 2012; GUEDES et al., 2017; ZINDA; ZHANG, 2017), o presente trabalho testa essas relações desde o início do projeto de assentamento, utilizando dados sobre os assentados e as características socioeconômicas, demográficas e de cobertura e uso do solo dos lotes rurais a partir do seu momento de chegada à fronteira.

A razão das evidências contraditórias observadas na literatura sobre efeitos demográficos nos estudos de uso e cobertura da terra que utilizam uma perspectiva micro advém da limitação dos dados em analisar essa relação no momento de estabelecimento das fronteiras. É exatamente na implantação das fronteiras agrícolas que essa associação é mais forte e evidente (VANWEY et al., 2007; MCCRAKEN et al., 1999), especialmente para o desmatamento (GUEDES et al., 2017). Tal limitação é superada nesse estudo pela utilização de dados coletados desde os momentos iniciais de estabelecimento dos primeiros colonos, no início dos anos 1980. Até onde sabemos, este é o único estudo a fornecer essa evidência para estágios iniciais da fronteira.

\section{Ciclos de vida e dinâmica da cobertura e uso da terra em fronteiras agrícolas}

Com base nos arcabouços de demografia formal (ELDER, 1985), a teoria do ciclo de vida domiciliar sugere que as dinâmicas observadas na cobertura e uso da terra seguem um padrão temporal previsível. Esse padrão reflete as diferentes fases e composições da estrutura etária dos domicílios agrícolas em estágios nos quais as instituições de mercado são pouco desenvolvidas ou inexistentes. Por essa razão, a capacidade de ofertar mão de obra é o fator-chave para determinar o nível de produção domiciliar que atenda aos seus requisitos de consumo (HAMMEL, 2005). Sob essa perspectiva, seria possível prever a extensão do desmatamento, o seu timing e o tipo de sistema agrícola apenas observando a evolução demográfica da fronteira, particularmente em termos da composição etária domiciliar (MCCRACKEN et al., 1999).

Segundo Chayanov, a extensão de terra cultivada é função do número de adultos e de dependentes em um domicílio rural, ao determinar sua capacidade de trabalho e sua 
necessidade de consumo. Como a razão trabalhador/consumidor (RTC) é uma função direta da estrutura etária domiciliar e essa estrutura modifica-se ao longo do tempo, Chayanov conclui que em domicílios com uma grande quantidade de adultos ou poucas crianças e idosos a RTC é elevada, possibilitando maior alocação de trabalho para as atividades agropecuárias (HAMMEL, 2005). Esse arcabouço fundamenta-se nos seguintes pressupostos: a terra tem custo desprezível; a tecnologia de produção é constante; toda a produção é consumida pelo domicílio, sem acumulação de capital; e não há integração da economia domiciliar com os mercados (THORNER et al., 1986).

As condições impostas pelo arcabouço de Chayanov são demasiadamente restritivas quando aplicadas à Amazônia brasileira contemporânea. Em primeiro lugar, os agricultores de fronteira são, em geral, migrantes em busca de algum tipo de ascensão social e material (BARBIERI et al., 2009; GUEDES et al., 2014). Em segundo lugar, há evidências de que várias fronteiras da Amazônia estão se integrando comercialmente com as economias nacional e global (BRONDÍZIO, 2008). Em terceiro, é comum a prática de venda e contratação de mão de obra paga entre os agricultores durante períodos críticos, como na derrubada de mata, no período de plantio e de colheita e na fase de limpeza do pasto (ALDRICH et al., 2006). Em função dessas especificidades do contexto amazônico, vários autores propuseram arcabouços modificados, ${ }^{1}$ os quais reconhecem explicitamente o papel dessas instituições (GUEDES et al., 2017; VANWEY et al., 2012a; CALDAS et al., 2007; WALKER, 2004; MCCRACKEN et al., 1999).

A relação entre ciclo de vida do domicílio e do lote inicia-se com a chegada de um jovem casal de colonos à fronteira e com a limpeza do lote. Inicialmente, o domicílio rural especializa-se na produção de culturas anuais, que possuem um retorno de curto prazo e representam uma fonte de baixo risco. Diante da abundância de terras e da limitação inicial de capital, o domicílio abre novas áreas a cada ano para manter a produção mínima de subsistência. À medida que se eleva o estoque de mão de obra domiciliar, aumenta o investimento em atividades comerciais (especialmente culturas perenes e criação de gado). A venda da produção nos mercados locais, ao capitalizar o domicílio rural, possibilita o reinvestimento na produção, intensificando suas relações com o mercado ao longo do tempo. McCraken et al. (1999) consideram ainda que, no estágio avançado do ciclo de vida

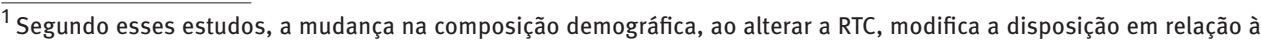
tomada de risco e à poupança para cada tipo específico de cultura. Esse é um ponto fundamental que diferencia o modelo original de Chayanov dos modelos contemporâneos sobre ciclo de vida e uso da terra. Para o primeiro, o domicílio tem o objetivo de maximizar o lazer, uma vez atendidos os requisitos de subsistência. Para os últimos, o domicílio passa a maximizar não somente o tempo livre, como também o excedente de produção para o mercado. Assim, num cenário de pós-fronteira, o indivíduo passa a procurar um excedente e começa a atuar com uma lógica essencialmente econômica, seja por meio da maximização do lucro, da minimização do risco ou de ambos (WALKER, 2004).
} 
(caracterizado por domicílios multigeracionais ou de segunda geração²), o desmatamento desaparece e há um aumento da área destinada à sucessão secundária, representando um investimento em madeira para a segunda geração.

Além desse efeito de composição representado pela composição etária do domicilio rural, há um outro componente de composição importante para entender a dinâmica da paisagem nas fronteiras. VanWey et al. (2007) sugerem que o tempo de permanência do domicílio na fronteira representa o grau de exposição dos agricultores ao ambiente biofísico e às instituições locais. Nesse sentido, cada coorte de assentamento ganha experiência agrícola ao longo do tempo, reduzindo a necessidade de experimentação com o solo. Na presença de rotação fundiária (property turnover), portanto, a fronteira em determinado ponto no tempo apresentará um conjunto de coortes de assentamento com diferentes conhecimentos locais, produzindo ondas de desmatamento (BRONDIZIO et al., 2002; RODRIGUES et al., 2009). Esse efeito é conhecido como "ciclo no lote", o qual permite ao agricultor maximizar o retorno da agricultura ao longo do tempo, especialmente nas fases intermediárias da fronteira, em que o sucesso na integração com os mercados locais incipientes pode ser determinante para sua sobrevivência (GUEDES et al., 2014).

Summers (2008) sugere que os ciclos de vida do domicílio e do lote interagem nos estágios iniciais, tornando-se difícil distingui-los. Guedes et al. (2017) propuseram um esquema conceitual que determina as trajetórias de efeitos desses ciclos ao longo do desenvolvimento das fronteiras agrícolas. Segundo os autores, a integração dos agricultores com os mercados reduz a influência do ciclo de vida domiciliar, uma vez que os domicílios podem contratar mão de obra paga com o surgimento dos mercados de trabalho locais. 0 ciclo no lote, no entanto, mantém-se importante apenas para o sucesso na escolha dos sistemas de uso do solo adequados às características biofísicas do solo, e não necessariamente para conter o desmatamento - se o estoque desmatado já é suficiente para atender aos sistemas agrícolas locais. Ademais, as propriedades multigeracionais beneficiam-se da transmissão intergeracional do capital específico da terra (RAAD; GUEDES, 2015), reduzindo a necessidade de desmatamento mesmo com pouco tempo de residência dos domicílios da segunda geração (BARBIERI et al., 2009).

\footnotetext{
$\overline{2}$ McCraken et al. (1999) definem domicílios multigeracionais como aqueles em que moram na mesma residência rural o proprietário, seu cônjuge e filhos (formando o núcleo domiciliar), além dos pais do proprietário e/ou do cônjuge e netos destes. Por exemplo, um domicílio rural formado por um proprietário, esposa, um filho e os pais desse proprietário seria considerado, por esta definição, multigeracional. Se em vez dos pais do proprietário morassem os seus netos, também seria considerado um domicílio multigeracional. Domicílios de segunda geração, por seu turno, são aqueles formados por filhos dos proprietários colonos (ou seja, dos colonos originais que chegaram à fronteira e receberam os lotes do Incra). Em alguns casos, pode ocorrer de um domicílio ser multigeracional, mas considerado de segunda geração; este é o caso em que o filho do colono assume a propriedade da casa e/ou do lote rural (VANWEY et al., 2007).
} 


\section{Metodologia}

\section{Área de estudo e dados}

O Projeto de Assentamento Machadinho d'Oeste (PA-MDO) é resultado de um projeto de colonização dirigida, aprovado no âmbito do Polonoroeste e implantado pelo Instituto Nacional de Colonização e Reforma Agrária (Incra) em 1982 (BARBIERI, et al. 2014; MIRANDA et al., 2015). Em 1984 teve início a ocupação dos terrenos agrícolas e, em 1987, o PA já continha mais de 1.500 domicílios, embora uma expressiva parte desses ainda estivesse inacabada ou funcionando como uma segunda residência para as famílias rurais (MONTE-MÓR, 2004). No presente trabalho foram utilizadas as informações obtidas por meio de entrevistas domiciliares realizadas durante um período de aproximadamente 30 anos no PA Machadinho d'Oeste, em Rondônia (Figura 1).

As entrevistas começaram por volta de 1985 e as últimas foram realizadas em 2015, totalizando seis ondas de informações. Para 1985, 1986, 1987 e 1995, as informações correspondem a todas as famílias de agricultores que compuseram o PA original, representando 281 lotes, 339 domicílios e 1.697 indivíduos em 1985, 504 lotes, 581 domicílios e 2.767 indivíduos em 1986, 765 lotes, 820 domicílios e 3.965 indivíduos em 1987 e, por fim, 1.078 domicílios, 946 lotes e 5.035 indivíduos em 1995 (Tabela 1). A expansão da população local é típica dos estágios iniciais das fronteiras agrícolas na Amazônia (VANWEY et al., 2007) e possibilitou uma rápida integração do assentamento com o núcleo urbano do município (MONTE-MÓR, 2004).

TABELA 1

Composição das amostras

Projeto de Assentamento Machadinho d’Oeste, Rondônia - 1985-1995

\begin{tabular}{cccccccc}
\hline \multirow{2}{*}{ Anos } & \multicolumn{3}{c}{ Universo } & & \multicolumn{3}{c}{ Amostra analítica } \\
\cline { 2 - 3 } \cline { 6 - 7 } & Domicílios & Lotes & Indivíduos & & Domicílios & Lotes & Indivíduos \\
\hline 1985 & 339 & 281 & 1.697 & & - & - & - \\
1986 & 581 & 504 & 2.767 & & - & - & - \\
1987 & 820 & 765 & 3.965 & & 804 & 732 & 3.889 \\
1995 & 1.078 & 946 & 5.035 & & 1.067 & 897 & 4.978 \\
\hline
\end{tabular}

Fonte: Levantamento domiciliar realizado em Machadinho d'Oeste. Elaboração dos autores.

Embora as pesquisas realizadas no PA-MDO cubram um período extenso, este estudo utiliza os dados censitários de 1987 e 1995 apenas. Entre 1985 e 1987 várias famílias deixaram a fronteira em função das adversidades iniciais, do mismatch entre o capital agrícola dos colonos e a qualidade da terra na qual foram assentados (CASTRO; SINGER, 2012) e, especialmente, da forte presença de malária na região (SAWYER, 1993). Barbieri et al. (2013), por exemplo, estimam que entre 1985 e 1987 apenas $61 \%$ das famílias originalmente presentes ainda permaneciam no local. Entre 1985 e 1995, o número de famílias originais era ainda menor (14\%). Para evitar comparar famílias de 1985 e 1986 com as de 1987 e 1995, introduzindo excessiva seletividade na análise, restringimos o estudo 
aos dois últimos anos. Esse período de oito anos é suficiente para viabilizar a análise do papel do ciclo de vida e do lote e ainda representa razoavelmente os dois estágios mais importantes no desenvolvimento da fronteira (estabelecimento e expansão) para entender a contribuição desses ciclos para a dinâmica de cobertura da terra, como sugerido por VanWey et al. (2012a).

Além dos dados das entrevistas domiciliares, foram utilizadas informações produzidas pelos projetos Land Use, Climate and Infections in Western Amazonia (LUCIA) e Dinâmica Demográfica e Uso da Terra na Amazônia: um Estudo Longitudinal para a Região de Machadinho, Rondônia, coordenados por pesquisadores do Centro de Desenvolvimento e Planejamento Regional (Cedeplar) da Universidade Federal de Minas Gerais (UFMG) e financiados, respectivamente, pelo Inter-American Institute for Global Environmental Research (IAI) e pelo Conselho Nacional de Desenvolvimento Científico e Tecnológico (CNPq).

FIGURA 1

Área de estudo e mapa de densidade populacional nas propriedades agrícolas Projeto de Assentamento Machadinho d’Oeste, Rondônia - 1987-1995

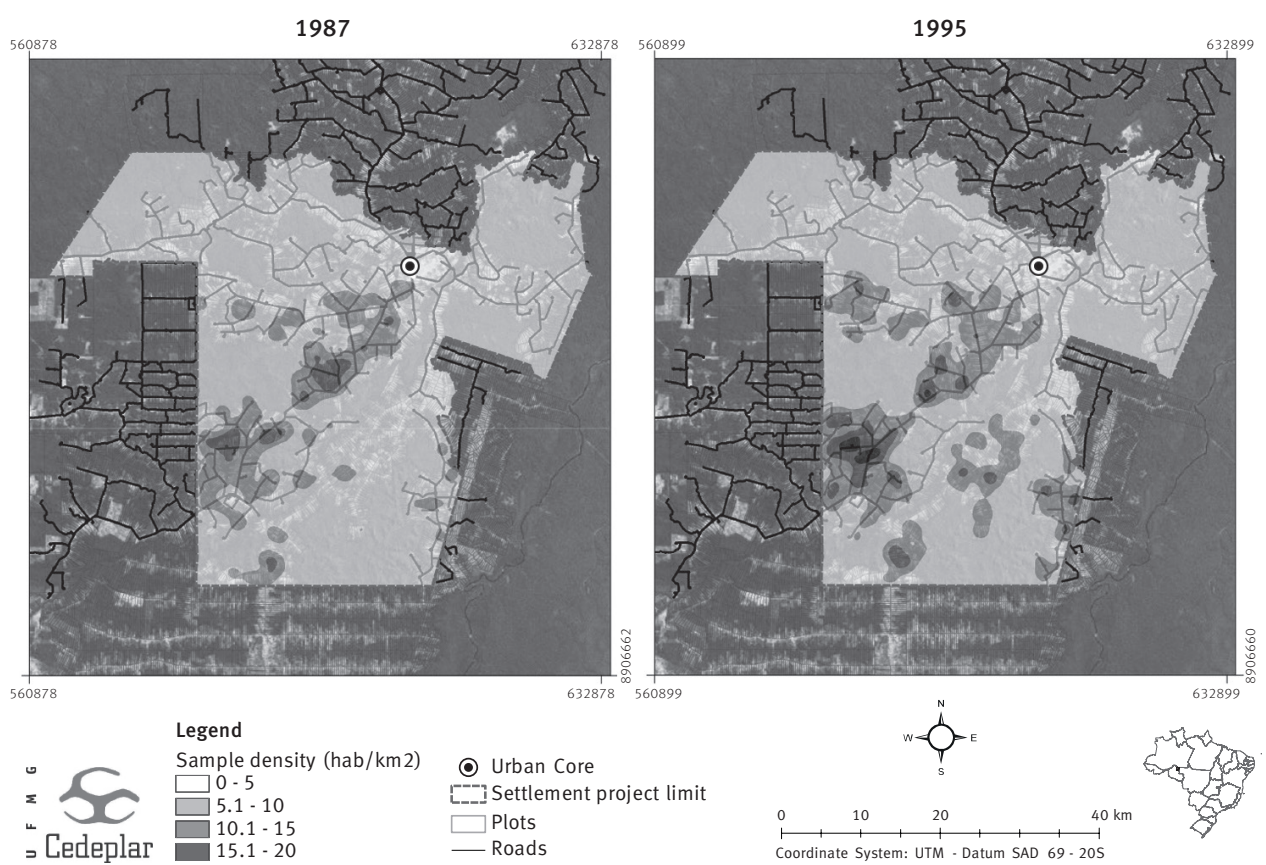

Fonte: Cedeplar (2014); IBGE (2010); Incra (1986). Elaboração dos autores.

Para o levantamento cartográfico, sobretudo das características do uso e cobertura do solo, foram empregadas imagens de satélite provenientes de sensores remotos, utilizando a constelação de satélites do programa LandSat. 0 Landsat 5 é o satélite que possui cobertura durante o período de realização das pesquisas de campo (em operação desde 1984 e operacional até 2011), sendo uma das principais fontes de dados para o trabalho. Seu sensor TM (Tematic Mapper) possui sete bandas, com numeração de 1 a 7 , sendo 
que cada banda representa uma faixa do espectro eletromagnético captada pelo satélite, que revisita (observa) a mesma área a cada 16 dias, captando em uma cena representada no solo de 185 x $185 \mathrm{~km}$. A resolução geométrica (área do pixel da imagem obtida pelo sensor) nas bandas 1 a 7 é de 30 × 30 m (isto é, cada "pixel" da imagem representa uma área no terreno de 0,09 ha).

A classificação foi construída com base na segmentação das imagens - classificação orientada a objeto -, utilizando-se todas as bandas disponíveis, exceto a banda termal, e com o uso de uma banda artificial. Essa última foi gerada a partir do Índice de Vegetação da Diferença Normalizada (NDVI). As classes criadas foram água, campo amazônico, culturas anuais, culturas perenes, floresta primária, floresta secundária, pasto, solo exposto e nuvens.

\section{Métodos}

Este artigo utilizou modelos que analisam o desmatamento e as classes de uso do solo (variáveis dependentes) como proporções da área total do lote. Essas proporções foram medidas de forma contínua e restrita ao intervalo $(0,1)$. 0 modelo teórico foi aplicado para o lote rural como unidade de análise, assim como é feito em vários outros estudos do gênero (GUEDES et al., 2017; CALDAS et al., 2007). Embora o interesse seja no efeito do ciclo de vida e do lote sobre a dinâmica da cobertura e uso do solo, utilizar o lote em vez do domicílio como unidade de análise justifica-se devido aos ganhos de escala nas decisões de produção agrícola (WALKER, 2003), bem como na interdependência decisória e produtiva comum em lotes multigeracionais, como já apontado por outros estudos (PAN; CARR, 2016; D’ANTONA et al., 2007; WALKER et al., 2002; PERZ, 2001), ou em nível comunitário como em certos contextos amazônicos (AMARAL et al., 2013). Embora vários outros artigos (PAN et al., 2007; MENA et al., 2006; PAN; BILSBORROW, 2005; WALKER, 2003) contemplem a intensidade do desmatamento (proporção), nenhum deles utiliza a abordagem descrita a seguir, a qual é a mais apropriada para lidar com variáveis medidas como taxas ou probabilidades (FERRARI; CRIBARI-NETO, 2004). A única exceção é o artigo de Guedes et al. (2017).

Existem duas classes de modelos para variáveis medidas como taxa ou proporção no intervalo $(0,1)$ : univariados e multivariados. Os primeiros são utilizados para modelar apenas uma taxa ou proporção, como no modelo de desmatamento. Quando o interesse é modelar simultaneamente várias taxas ou proporções que apresentam interdependência negativa (o aumento de uma delas implica a redução das demais), a modelagem deve empregar uma distribuição multivariada (conjunta), que explicitamente considere a estrutura não nula de covariância entre as equações (FERRARI; CRIBARI-NETO, 2004).

Os principais modelos univariados para taxas ou proporções são: Beta; Logístico Fraccional Binário Generalizado (LFBG); e Beta Zero-Um Inflado (BZUI). 0 modelo de regressão Beta é adaptado às situações em que a variável dependente ( $y$ ) é medida continuamente 
no intervalo de unidade padrão, isto é, $O<y<1$. 0 pressuposto do modelo é que a resposta é beta distribuída. Interpretam-se os parâmetros estimados em termos da média da variável resposta - ou seja, quanto, em média, a proporção ou a taxa varia em função de uma variação no preditor.

Um problema da regressão beta é o fato de trabalhar com a variável dependente apenas no intervalo $0<y<1$, ou seja, ela ignora os valores extremos ( 0 e 1). Há duas soluções para a incorporação desses valores: considerar os valores 0 e 1 como proporções muito baixas ou muito altas, em que sua ocorrência se dá por meio do mesmo processo gerador das demais proporções; e considerar os valores 0 e 1 gerados por processos distintos daqueles experimentados pelas demais proporções, o que implica valores de beta zero-um inflado. A primeira estratégia dá origem ao modelo LFBG e, a segunda, ao modelo BZUI. A escolha do melhor modelo depende de testes e observação descritiva dos dados. A primeira evidência é obtida com uma descrição da proporção de eventos concentrados em 0 e 1. Caso a densidade nesses dois pontos seja muito pequena, é pouco provável que se tenham ganhos significativos na utilização dos modelos BZUI. ${ }^{3} 0$ cálculo da média e da variância empíricas também é uma forma de sinalizar a necessidade de utilização do modelo LFBG. ${ }^{4}$

Para o caso da modelagem simultânea de proporções interdependentes, há dois tipos de modelo: aquele baseado na Distribuição de Probabilidade Dirichlet; e o modelo Logístico Fraccional Multinomial Generalizado (LFMG). Esses modelos são extensões multivariadas dos modelos Beta e LFBG, respectivamente. 0 primeiro é útil quando há poucos casos de valores 0 e 1 para todas as proporções e não existe interesse em modelar a correlação das variâncias conjuntas (ou quando essas são bem-comportadas). 0 segundo incorpora covariâncias não nulas e variâncias heterocedásticas, além de incluir os valores 0 e 1 como parte do mesmo processo gerador. A escolha do melhor modelo segue inspiração similar ao caso univariado. A estimação de todos esses modelos é realizada por máxima verossimilhança, com interpretação, portanto, estritamente assintótica.

\section{Estratégia de estimação}

Dois critérios para a escolha do modelo mais adequado foram utilizados: análise descritiva das variáveis dependentes; e transformação da variável conforme proposto por Smithson e Verkuilen (2006). No primeiro caso, observaram-se os valores absolutos e relativos de 0's e 1's na proporção da área desmatada e demais classes agregadas para ambos os anos. Em 1987, nenhum dos 732 lotes possuía cobertura vegetal intacta e apenas oito lotes estavam completamente desmatados. ${ }^{5} \mathrm{Em} 1995$, apenas 23 dos 897 lotes estavam

\footnotetext{
$\overline{3} 0$ teste para a comparação entre os dois modelos anteriores e o modelo zero-um inflado é mais complexo, mas segue uma inspiração similar ao teste proposto por Vuong (1989) para modelos não aninhados (GREENE, 1994).

${ }^{4}$ Embora a média e a variância condicionais possam levar a conclusões distintas, o que requer o auxílio de um teste de razão de verossimilhança para equidispersão. Neste caso, a estatística de teste é definida como $G^{2}=2 \ln \left(L_{G L M}\right)-2 \ln \left(L_{B E T A}\right)$ $\sim X^{2}(1)$. Se $G^{2} X_{c}^{2}$ tem-se evidência estatística de superdispersão, sugerindo o uso do modelo generalizado.

${ }^{5}$ Apenas 19 possuíam $0 \%$ em uso comercial e 370 em uso sob culturas anuais.
} 
completamente desmatados e nenhum completamente intacto. ${ }^{6}$ Assim, a análise descritiva das variáveis dependentes sinaliza para o uso do modelo Beta para o caso univariado (modelo de desmatamento) e da Distribuição de Dirichlet para o caso multivariado (modelo de usos do solo). Para garantir a inclusão desses lotes com proporções 0 e 1, aplicou-se a transformação proposta por Smithson e Verkuilen (2006), baseada na seguinte fórmula:

$y_{t}^{*}=\frac{y_{t} \times\left(n_{t}-1\right)+0,5}{n_{t}}$

Onde: $y_{t}$ é a variável dependente no ano $t$ e $n_{t}$ é o tamanho amostral no mesmo ano.

Os modelos utilizaram uma amostra analítica de 732 e 897 lotes em 1987 e 1995, respectivamente. A diferença com as amostras originais (745 e 915) deve-se à falta de informações para o ano de chegada ao lote. Uma análise de seletividade amostral, comparando os valores médios, e um teste de diferença de médias entre a amostra excluída e a amostra analítica indicaram diferenças não significativas.

\section{Definição das variáveis do modelo}

\section{Variáveis dependentes}

A área desmatada foi mensurada em hectares e restrita à área do lote agrícola. Para sua obtenção, foram empregados os dados classificados a partir de sensoriamento remoto para cobertura do solo (ver detalhes na seção Dados). A área desmatada foi construída subtraindo da área total a área em floresta primária. A intensidade do desmatamento foi definida como a proporção da área desmatada, calculada como a relação entre a área desmatada e a área total em cada lote. As demais classes de uso foram definidas da seguinte forma: uso comercial, ${ }^{7}$ que representa a agregação das áreas em pasto, solo exposto e culturas perenes; uso de subsistência, que corresponde às áreas em culturas anuais; floresta primária; e "outros usos”, que englobam as demais classes. Todas essas classes estão expressas em hectares para fins descritivos e como proporção do lote quando usadas como variáveis dependentes.

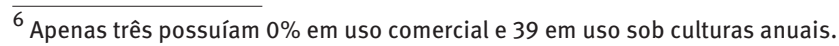

${ }^{7}$ Muitos estudos utilizam a definição clássica da FAO (Food and Agriculture Organization of the United Nations) para sistemas comerciais e de subsistência (WALKER et al., 2002; BROWDER et al., 2004). 0 conceito de sistema agrícola da FAO é baseado na combinação das classes de cobertura e uso da terra acrescida das características (quantidade e destinação) da produção, além de outros elementos da organização da produção - como os tipos de mão de obra utilizada na produção e a divisão sexual do trabalho agrícola e doméstico (DIXSON, 2001). Nesse sentido, o conceito de uso comercial e de subsistência depende do destino da produção (se para autoconsumo, mercado ou ambos). Neste estudo a classificação de uso comercial e de subsistência foi feita de forma ad hoc, uma vez que não há informação sobre o destino da produção para um dos anos utilizados. Agradecemos ao parecerista anônimo por chamar a atenção para a limitação do conceito de uso comercial por meio apenas das classes derivadas da classificação das imagens de satélite. Em defesa da tipologia aqui adotada, no entanto, observamos que as culturas perenes e as pastagens são concentradas nos lotes com destinação comercial da produção. Barbieri et al. (2013), por exemplo, utilizando dados de 1995 até 2010 para a mesma área de estudo, os quais contêm essa informação, revelam uma correlação positiva entre as classes que definimos como comercial e a alta proporção da produção agrícola destinada à venda nos mercados locais, embasando nossa classificação ad hoc.
} 


\section{Variáveis independentes}

Seguindo agrupamentos utilizados em estudos similares (ZINDA; ZHANG, 2017; GUEDES et al., 2017; CALDAS et al., 2007; VANWEY et al., 2007; BARBIERI et al., 2005; WALKER, 2003), as variáveis independentes foram organizadas em quatro grupos: ciclo de vida domiciliar; ciclo de vida no lote; integração com mercado; e variáveis controle.

Como indicadores de ciclo de vida domiciliar foram utilizadas as seguintes variáveis: idade do chefe do lote; ${ }^{8}$ e número de crianças (até nove anos), adultos (10 a 59 anos) e idosos (acima de 60 anos) no lote. ${ }^{9}$ A idade do chefe indica a experiência passada com atividades agrícolas, independentemente da experiência adquirida na região (PERZ; WALKER, 2002; CALDAS et al., 2007), podendo estar tanto positiva quanto negativamente relacionada com o desmatamento. A relação positiva reflete a demanda por terra (WALKER, 2003), ao passo que a negativa demonstra experiência agrícola, reduzindo a necessidade de área adicional para cultivo (GUEDES et al., 2011).

0 número de adultos no lote representa a força de trabalho familiar em potencial. A literatura sugere uma relação positiva entre o número de adultos no lote e os indicadores de desmatamento (MCCRAKEN et al., 1999; VANWEY et al., 2007). A quantidade de crianças, pré-adolescentes, adolescentes e idosos no lote é uma proxy para a dependência ou necessidade de consumo domiciliar (HAMMEL, 2005). Assim como ocorre para a idade do chefe, o total de dependentes pode ter um efeito dúbio sobre o desmatamento. Em geral, estudos empíricos mostram que uma maior razão de dependência jovem eleva o desmatamento devido ao crescimento inicial das necessidades de consumo de domicílios jovens na fronteira (CABRERA et al., 2012), embora dependa do momento em que esses domicílios entraram na fronteira (GUEDES et al., 2017; BRONDIZIO et al., 2002). 0 efeito da razão de dependência de idosos sobre o desmatamento também pode variar. Em casos em que o sistema de uso do solo é predominantemente extensivo com baixa necessidade de mão de obra (gado, por exemplo) (empty nest scenario), o efeito é positivo (WALKER et al., 2000). Quando, por outro lado, há lotes com múltiplos domicílios familiares (generational shift scenario), o sistema do solo intensivo em mão de obra tende a prevalecer, reduzindo a necessidade por áreas desmatadas adicionais (PERZ, 2001; WALKER et al., 2002; BROWDER et al., 2004).

\footnotetext{
${ }^{8}$ Quando havia mais de um domicílio por lote, foi considerada a média simples entre as idades dos chefes desses domicílios pertencentes ao mesmo lote.

${ }^{9}$ Foram testados outros marcadores, como a razão de dependência do lote (idosos e jovens divididos pelo número de adultos) e o número de dependentes ( 0 a 14 anos e 60 anos e mais) no lote. No entanto, as variáveis desagregadas por grupos etários produziram modelos mais bem ajustados aos dados e refletem aproximadamente a forma de introdução de grupos de idade em outros estudos (VANWEY et al., 2007; ZINDA; ZHANG, 2017). Outros agrupamentos etários foram testados, como número de pré-adolescentes (de 10 a 12 anos) e adolescentes (de 13 a 14 anos). Como a proporção de pessoas entre 10 e 14 anos que participavam de atividades agrícolas no lote era alta, esses indivíduos foram considerados junto com os demais adultos. Agrupamentos similares foram feitos em outros estudos para fronteiras amazônicas (VANWEY et al., 2007; VANWEY; VITHAYATHIL, 2013).
} 
Como em VanWey et al. (2007) e Barbieri et al. (2005), o tempo de residência no lote foi o marcador utilizado neste estudo para o ciclo no lote. Ao contrário da idade do chefe, o tempo de residência é considerado uma forma de conhecimento específico ao lote (ou place-specific capital, como sugerido por Sherbinin et al., 2008), reduzindo a necessidade de experimentação com a terra (MORAN et al., 2006; CASTRO; SINGER, 2012). Embora Guedes et al. (2017) sugiram uma diferenciação entre ciclo do lote e ciclo no lote, a ausência de informação sobre classificação anual da cobertura florestal por imagem de satélite na área de assentamento de Machadinho d'Oeste inviabiliza esse tipo de desagregação no presente estudo. Portanto, o efeito de ciclo do lote aqui deve ser interpretado de forma análoga ao ciclo no lote. Por outro lado, como os dados utilizados correspondem aos estágios iniciais da fronteira, esses dois ciclos são virtualmente idênticos, fazendo com que o viés de omissão seja desprezível para a especificação aqui utilizada.

Dois indicadores de integração com os mercados foram usados: distância ao centro urbano; e proporção da produção agrícola destinada à venda. A distância com relação ao núcleo urbano de Machadinho, medida em quilômetros a partir do centroide de cada lote entrevistado, foi utilizada para aproximar as influências externas sobre a utilização da terra e o grau de conexão da fronteira com os mercados externos (TURNER II, 2001). Enquanto esta distância expressa a relação entre custo e retorno da prática agrícola destinada ao mercado, a proporção da produção vendida é uma medida que aproxima a intensidade dessa relação ou o grau de dependência do lote com relação ao mercado (CALDAS et al., 2007; SUMMERS, 2008). Devido à pequena escala da produção agrícola dos lotes rurais no PA Machadinho, a distância até o seu núcleo urbano é uma boa aproximação para a conexão desses lotes com os mercados locais. Monte-Mór (2004), por exemplo, mostra que, embora as influências externas já eram notadas na região (equipamentos e mesmo alguma produção agrícola que eram adquiridos pelos domicílios rurais vindo de regiões relativamente distantes de Rondônia ou de outros estados brasileiros), o limite de escoamento da produção local e o grosso da demanda estavam circunscritos aos mercados urbanos locais, concentrados na cidade de Machadinho.

\section{Resultados}

\section{Análise descritiva}

A Tabela 2 mostra as estatísticas descritivas das variáveis dependentes e independentes para os dois anos analisados. As duas últimas colunas para cada ano representam um teste de associação bivariada entre a variável dependente principal (\% desmatado ou \% em uso comercial) e cada uma das variáveis independentes. De modo geral, observa-se uma tendência bastante consistente com os arcabouços conceituais sugeridos por Guedes et al. (2017), Caldas et al. (2007) e Walker (2004). 0 estoque de desmatamento aumenta ao longo dos anos, passando de uma média de $22 \%$ para $55 \%$. A área em uso comercial, 
especialmente pasto e culturas perenes, aumenta quase três vezes neste período (de $13 \%$ para $32 \%$ ). 0 tamanho do lote se alterou pouco ao longo do tempo, de 45,1 para 44,9 hectares entre 1987 e 1995. Os indicadores de ciclo de vida domiciliar e do lote sugerem um envelhecimento das famílias na fronteira, como esperado. 0 número médio de crianças reduz-se ligeiramente (de 1,6 para 1,4), compensado pelo aumento de adultos (de 3,5 para 3,9) e idosos (de 0,1 para 0,2). 0 aumento médio de apenas 4,4 anos de residência no lote entre 1987 e 1995 sugere um efeito turnover de proprietários no período, típico dos estágios iniciais da fronteira. Como houve pouca alteração nos indicadores de estrutura etária domiciliar, os resultados sugerem uma renovação dos domicílios com estrutura etária semelhante no momento de chegada ao longo do tempo, conforme reportado em diversos estudos para outras fronteiras da Amazônia (BRONDIZIO et al., 2002; PAN; CARR, 2016; GUEDES et al., 2017).

0 desenvolvimento da fronteira reflete-se também no perfil socioeconômico dos proprietários. A escolaridade média quase dobrou no período (de 1,5 para 2,5 anos), embora tenha continuado muito baixa. Um aspecto peculiar do PA Machadinho é a natureza urbana do início de seu assentamento. Diferentemente de outras regiões de assentamento planejado, Machadinho já nasceu vinculado a um núcleo urbano (MONTE-MÓR, 2004), o que reflete o elevado percentual de renda não agrícola dos agricultores em 1987 (72\%). Em 1995, essa proporção era de apenas 25\%, sugerindo uma trajetória de ruralização do assentamento. Se olharmos para as correlações ao longo do tempo, percebemos um enfraquecimento da associação entre desmatamento e indicadores de ciclo de vida e aumento da associação para indicadores de integração com mercado e características relativas ao capital financeiro. 0 mesmo é observado para o uso comercial do solo. Esses resultados, novamente, refletem os padrões sugeridos pelo arcabouço teórico apresentado em de Sherbinin et al. (2008) e VanWey et al. (2012a).

O Gráfico 1 apresenta uma análise dos padrões de cobertura e uso do solo por coortes de assentamento (utilizado neste artigo como ciclo no lote). Exatamente como reportado em Brondízio et al. (2002) e Guedes et al. (2017) para as fronteiras agrícolas de Santarém e Altamira (Pará), e em Summers (2008) para Alto Paraíso, Nova União e Rolim de Moura (Rondônia), observa-se um comportamento senoidal da intensidade do uso/cobertura do solo no PA Machadinho. Podem-se observar dois "pulsos" de desmatamento, um nos anos iniciais de chegada ao lote e outro aproximadamente seis anos mais tarde. Esses pulsos também são replicados para o uso da terra para fins comerciais e de subsistência.

Três explicações têm sido apresentadas na literatura para esse comportamento por coortes: as novas oportunidades geradas pela integração das fronteiras com os mercados (BROWDER et al., 2004; SUMMERS, 2008); a mudança de um cenário macroeconômico adverso durante os anos 1980 para um cenário mais favorável e com estabilização econômica e retorno do crédito subsidiado na década de 1990 (BRONDIZIO et al., 2002); e os ciclos naturais de expansão, consolidação, retração e renascimento das "cidades rurais" da Amazônia (RODRIGUES et al., 2009). 0 padrão recorrente para diferentes áreas de estudo, 
no entanto, parece sugerir uma mistura de comportamento de coorte e efeitos potenciais de land turnover sobre a dinâmica da paisagem local (VANWEY et al., 2012b).

TABELA 2

Estatísticas descritivas e análise bivariada

Projeto de Assentamento Machadinho d’Oeste, Rondônia - 1987-1995

\begin{tabular}{|c|c|c|c|c|c|c|}
\hline \multirow[b]{2}{*}{ Variáveis } & \multicolumn{3}{|c|}{$1987(\mathrm{~N}=732)$} & \multicolumn{3}{|c|}{$1995(\mathrm{~N}=897)$} \\
\hline & Média & $\begin{array}{c}\rho \\
\text { (Desmatamento) }\end{array}$ & $\begin{array}{c}\rho \\
\text { (Uso } \\
\text { comercial) }\end{array}$ & Média & $\begin{array}{c}\rho \\
\text { (Desmatamento) }\end{array}$ & $\begin{array}{c}\rho \\
\text { (Uso } \\
\text { comercial) }\end{array}$ \\
\hline \multicolumn{7}{|l|}{ Uso e cobertura do solo } \\
\hline Floresta primária (\%) & 0,78 & 1,0000 & $-0,5040^{\star}$ & 0,45 & 1,0000 & $-0,6729 *$ \\
\hline Uso comercial (\%) & 0,13 & $-0,5040^{\star}$ & 1,0000 & 0,32 & $-0,6729 *$ & 1,0000 \\
\hline Uso para subsistência (\%) & 0,03 & $-0,3624^{\star}$ & $-0,1131^{\star}$ & 0,20 & $-0,4500^{\star}$ & $-0,1153^{*}$ \\
\hline Demais áreas (\%) & 0,06 & $-0,8002^{\star}$ & 0,0028 & 0,04 & $-0,2697^{\star}$ & $-0,1519 *$ \\
\hline Floresta primária (ha) & 35,12 & $0,7458^{*}$ & $-0,4683^{\star}$ & 20,35 & $0,9067^{\star}$ & $-0,6017^{\star}$ \\
\hline Uso comercial (ha) & 5,58 & $-0,4858^{\star}$ & $0,9464^{*}$ & 14,04 & $-0,5825^{\star}$ & $0,9117^{*}$ \\
\hline Uso para subsistência (ha) & 1,52 & $-0,3404^{\star}$ & $-0,1319 *$ & 8,67 & $-0,4014^{\star}$ & $-0,1348^{\star}$ \\
\hline Demais áreas (ha) & 2,83 & $-0,7739 *$ & $-0,0137$ & 1,85 & $-0,2584^{\star}$ & $-0,1523^{\star}$ \\
\hline Tamanho do lote (ha) & 45,06 & $0,0827^{\star}$ & $-0,2040^{\star}$ & 44,91 & $0,1527^{\star}$ & $-0,0897^{\star}$ \\
\hline \multicolumn{7}{|l|}{ Ciclo de vida domiciliar } \\
\hline Idade do chefe (anos) & 39,84 & $-0,0367$ & 0,0201 & 42,83 & $-0,0305$ & 0,0206 \\
\hline $\begin{array}{l}\text { Pessoas de } 0 \text { a } 9 \text { anos } \\
\text { (número) }\end{array}$ & 1,59 & 0,0675 & 0,0211 & 1,36 & $-0,0191$ & $-0,0273$ \\
\hline $\begin{array}{l}\text { Pessoas de } 10 \text { a } 59 \text { anos } \\
\text { (número) }\end{array}$ & 3,49 & $-0,1353^{*}$ & $0,2434^{*}$ & 3,86 & $-0,1858^{\star}$ & 0,0353 \\
\hline $\begin{array}{l}\text { Pessoas de } 60 \text { anos e mais } \\
\text { (número) }\end{array}$ & 0,13 & $-0,0038$ & 0,0362 & 0,19 & $-0,0904^{\star}$ & 0,0371 \\
\hline $\begin{array}{l}\text { Razão de dependência } \\
\text { domiciliar }\end{array}$ & 0,57 & $0,1075^{\star}$ & $-0,0805^{\star}$ & 0,48 & 0,0638 & $-0,0312$ \\
\hline \multicolumn{7}{|l|}{ Ciclo de vida no lote } \\
\hline $\begin{array}{l}\text { Tempo de residência no } \\
\text { lote (anos) }\end{array}$ & 1,69 & $-0,0632$ & $0,1031^{\star}$ & 6,11 & $-0,1281^{\star}$ & $0,0957^{*}$ \\
\hline \multicolumn{7}{|l|}{ Variáveis de controle } \\
\hline $\begin{array}{l}\text { Distância até o centro } \\
\text { urbano }(\mathrm{km})\end{array}$ & 23,70 & $0,2526^{*}$ & 0,0331 & 24,57 & $0,0706^{*}$ & 0,0502 \\
\hline $\begin{array}{l}\text { Renda agrícola (\% da renda } \\
\text { familiar) }\end{array}$ & 0,33 & $-0,0132$ & 0,0433 & 0,69 & $-0,1440^{\star}$ & 0,0524 \\
\hline $\begin{array}{l}\text { Renda não agrícola (\% da } \\
\text { renda familiar) }\end{array}$ & 0,72 & 0,0540 & $-0,1104^{\star}$ & 0,25 & $0,1277^{*}$ & $-0,0091$ \\
\hline $\begin{array}{l}\text { Renda familiar (unidades } \\
\text { monetárias) }\end{array}$ & $3.272,82$ & $-0,0825^{\star}$ & $0,0940^{\star}$ & 3733,73 & $-0,2371^{\star}$ & $0,1359 *$ \\
\hline
\end{tabular}

Fonte: Levantamento domiciliar realizado em Machadinho d’Oeste, 1987, 1995. Elaboração dos autores.

Nota: ${ }^{* *} p<0,01,{ }^{*} p<0,05,+p<0,1$. 


\section{GRÁFICO 1}

Proporção do lote, por diferentes usos e cobertura do solo e intervalo de confiança (95\%), segundo coorte de chegada à propriedade

Projeto de Assentamento Machadinho d’Oeste, Rondônia - 1987-1995
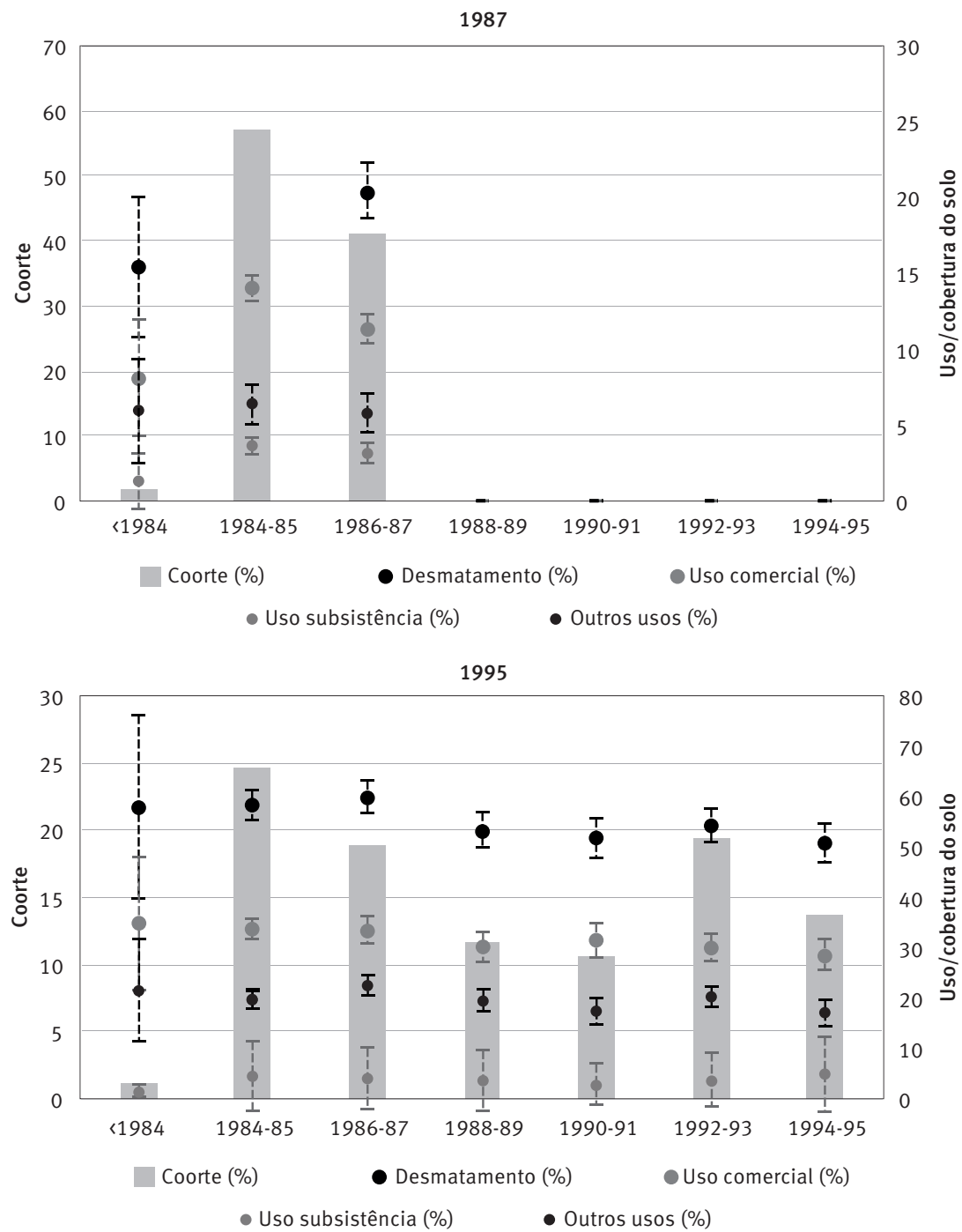

Fonte: Levantamento domiciliar realizado em Machadinho d’Oeste, 1987, 1995. Elaboração dos autores. Nota: Desmatamento = todas as áreas sem mata primária na propriedade rural.

\section{Análise inferencial}

Embora as associações bivariadas descritas na Tabela 2 sugiram uma relação consistente entre os ciclos de vida domiciliar, ciclo no lote e uso e cobertura do solo em Machadinho, essas relações podem estar capturando uma relação simultânea com outros determinantes. 
A Tabela 3 apresenta os coeficientes estimados (razões de chance) para a proporção da área desmatada e para a proporção do lote segundo classes agregadas de uso do solo.

Reforçando as evidências já apontadas pela Tabela 2, o efeito dos indicadores de ciclo de vida aumenta entre 1987 e 1995 em relação ao desmatamento e reduz-se em relação às áreas em uso comercial. 0 efeito negativo e significativo para a idade do chefe sobre 0 desmatamento em ambos os anos sugere um efeito de experiência agrícola, o que implica a redução da necessidade de área adicional para cultivo. Esse efeito negativo é também observado em relação à área em culturas comerciais (pasto e perene) em 1987, mas não em 1995. A perda de significância provavelmente reflete a mudança nos sistemas de uso do solo, predominantemente concentrados em culturas anuais e perenes nos estágios iniciais, alterando-se gradualmente para pasto com gado em estágios mais avançados (BARBIERI et al., 2016). Essa mudança é comum em fronteiras agrícolas com predominância de lotes unigeracionais envelhecidos (empty nest), uma vez que a criação extensiva de gado é lucrativa, apresenta alta liquidez e exige uma quantidade reduzida de mão de obra (WALKER et al., 2000).

O marcador de ciclo no lote tem um efeito não linear, aumentando a demanda por terra nos primeiros anos de residência (especialmente nos estágios iniciais da fronteira), seguido por um declínio progressivo. Esse efeito é consistente com a hipótese de learning-by-doing (capital específico da terra), também sugerido e observado em outros estudos (GUEDES et al., 2017; BARBIERI et al., 2005). 0 Gráfico 2 explora em maior profundidade os efeitos do ciclo no lote sobre a demanda por terra segundo diferentes classes de uso do solo. Para ambos os anos, a não linearidade da relação entre tempo de residência no lote e dinâmica da terra é evidente. A forma dessa relação também não se altera significativamente no período (coortes de 0 a 7 anos em 1987 e 8 a 15 anos em 1995), mesmo quando novas coortes de assentados chegam à fronteira.

Nos primeiros anos, há uma intensificação de demanda por terra (desmatamento), refletindo uma fase de experimentação com o ambiente agrícola (MORAN et al., 2006). Essa demanda adicional por terra já não aparece para as novas coortes em 1995, em que a tendência é de decrescimento desde os primeiros anos. Tal resultado sugere um "efeito aprendizado" das coortes novas em estágios mais avançados da fronteira (VANWEY et al., 2012a). Essa demanda adicional reflete predominantemente o aumento das áreas para atividades comerciais. ${ }^{10}$

Entre agricultores mais antigos a demanda adicional por terra é menor e a tendência continua, mesmo num período longo de permanência (valores simulados). Esse resultado é consistente com duas possíveis explicações causais: aumento do capital específico da terra, como advogado por de Sherbinin et al. (2008) e VanWey et al. (2012a); e sistemas de uso menos intensivo em terra, em que o desmatamento tende a ser menor (BROWDER

\footnotetext{
${ }^{10}$ Provavelmente dominada pela formação de pasto. Veja que a demanda adicional tem valor quase idêntico para desmatamento e área comercial. Na Amazônia, o predomínio de gado criado de forma extensiva justifica a correspondência entre as demandas marginais (WALKER et al., 2000).
} 
et al., 2004; ZINDA; ZHANG, 2017). A rigor, lotes mais antigos em Machadinho parecem se especializar em cultivo de culturas perenes, as quais demandam menos terra e mais mão de obra (BARBIERI et al., 2013). A demanda adicional para uso em culturas anuais permanece pequena ao longo do tempo, refletindo seu baixo potencial de mercado (cultura de subsistência).

GRÁFICO 2

Variação percentual estimada na cobertura e no uso do solo, segundo o tempo de residência no lote Projeto de Assentamento Machadinho d’Oeste, Rondônia - 1987-1995
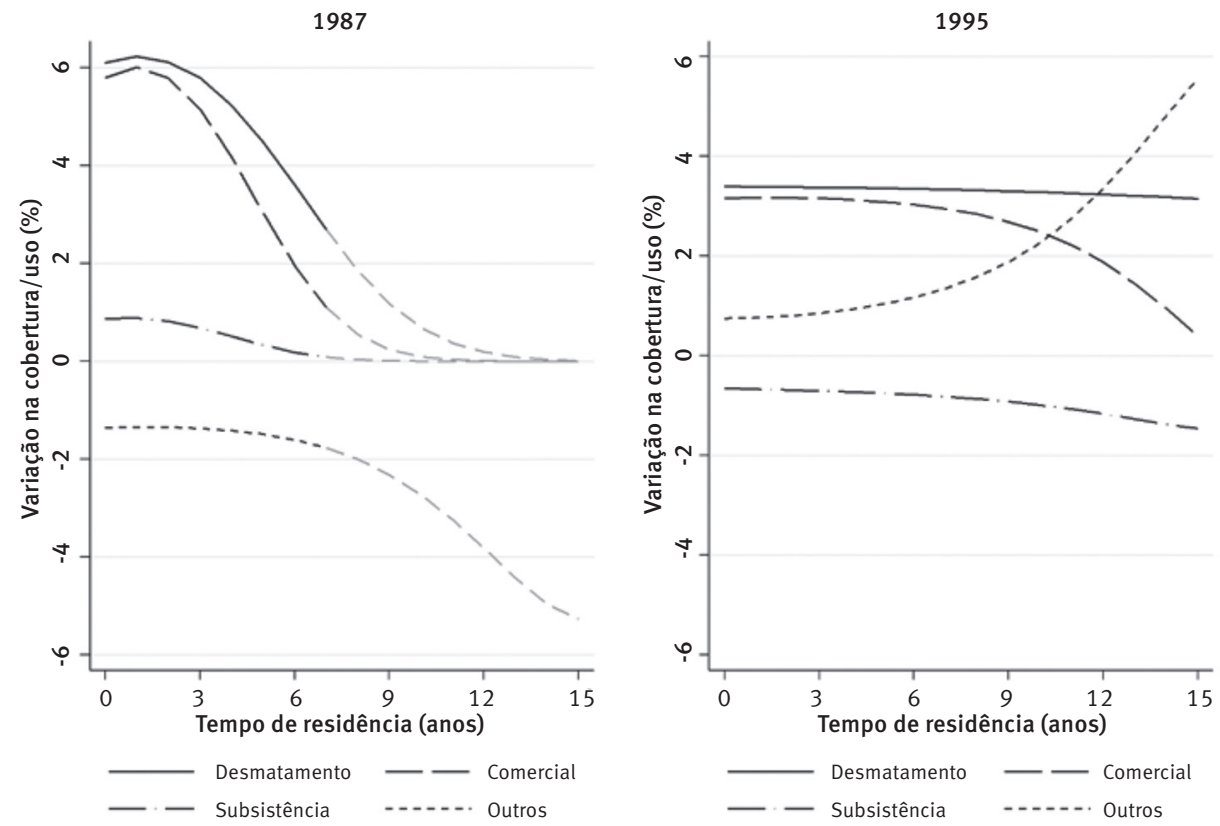

Fonte: Levantamento domiciliar realizado em Machadinho d'Oeste, RO - 1987, 1995. Elaboração dos autores.

Nota: Para 1987, os valores de mudança na cobertura e no uso do solo entre os que têm tempo de residência maior do que sete anos são simulados, seguindo a forma funcional estimada pela distribuição de Dirichlet.

0 aumento da área para outros usos em 1995 reflete tanto um efeito rotatividade do solo, como sugerido por D’Antona et al. (2006), quanto um aumento de áreas em sucessão secundária - comuns em domicílios envelhecidos (empty nest), como argumentado por Perz (2001). Infelizmente, os dados utilizados neste artigo não permitem decompor esses dois efeitos, os quais exigem um longo período de observação longitudinal para a estimação das matrizes de transição das classes de uso do solo. Por outro lado, há uma clara sinalização de que o efeito do ciclo no lote reduz a pressão sobre as florestas primárias remanescentes na medida em que a experimentação com a terra cede lugar a uma estratégia de uso do solo mais coerente com as características biofísicas do lote. Embora os dados aqui utilizados reflitam uma janela temporal muito defasada no tempo, resultados 
idênticos foram encontrados, empregando-se dados mais recentes para outras fronteiras agrícolas amazônicas com características similares (PAN; CARR, 2016; VANWEY et al., 2007). 0 modelo conceitual sugerido por Guedes et al. (2017), assim como os resultados empíricos derivados desse modelo, sugere que esse efeito é atenuado, mas não eliminado, em estágios mais avançados da fronteira.

TABELA 3

Razões de chance estimadas para os modelos de cobertura e uso do solo Projeto de Assentamento Machadinho d’Oeste, Rondônia - 1987-1995

\begin{tabular}{|c|c|c|c|c|c|c|c|c|}
\hline \multirow{3}{*}{ Variáveis } & \multirow{2}{*}{\multicolumn{2}{|c|}{$\begin{array}{c}\text { Distribuição Beta } \\
\begin{array}{c}\text { Desmatamento } \\
(\%)\end{array} \\
\end{array}$}} & \multicolumn{6}{|c|}{ Distribuição de Dirichlet [base = mata primária (\%)] } \\
\hline & & & \multicolumn{2}{|c|}{$\begin{array}{c}\text { Perene + Pasto } \\
(\%)\end{array}$} & \multicolumn{2}{|c|}{ Anuais (\%) } & \multicolumn{2}{|c|}{ Outros usos (\%) } \\
\hline & 1987 & 1995 & 1987 & 1995 & 1987 & 1995 & 1987 & 1995 \\
\hline \multicolumn{9}{|l|}{$\begin{array}{l}\text { Ciclo de vida } \\
\text { domiciliar }\end{array}$} \\
\hline Idade do chefe (anos) & $\begin{array}{l}0,998 \\
(0,004)\end{array}$ & $\begin{array}{l}\mathbf{0 , 9 9 4 +} \\
(0,003)\end{array}$ & $\begin{array}{l}0,994+ \\
(0,004)\end{array}$ & $\begin{array}{l}1,006 \\
(0,008)\end{array}$ & $\begin{array}{l}0,996 \\
(0,003)\end{array}$ & $\begin{array}{l}0,991^{*} \\
(0,004)\end{array}$ & $\begin{array}{l}1,001 \\
(0,003)\end{array}$ & $\begin{array}{l}1,000 \\
(0,004)\end{array}$ \\
\hline $\begin{array}{l}\text { Pessoas de } 0 \text { a } 9 \\
\text { anos (número) }\end{array}$ & $\begin{array}{l}\mathbf{0 , 9 2 2 * *} \\
(0,021)\end{array}$ & $\begin{array}{l}0,961^{\star} \\
(0,019)\end{array}$ & $\begin{array}{l}\mathbf{0 , 9 6 1 *} \\
(0,019)\end{array}$ & $\begin{array}{l}\mathbf{0 , 8 7 4} 4^{\star \star} \\
(0,038)\end{array}$ & $\begin{array}{l}0,960+ \\
(0,022)\end{array}$ & $\begin{array}{l}0,954^{*} \\
(0,021)\end{array}$ & $\begin{array}{l}0,940^{\star *} \\
(0,016)\end{array}$ & $\begin{array}{l}0,914^{\star *} \\
(0,019)\end{array}$ \\
\hline $\begin{array}{l}\text { Pessoas de } 10 \text { a } 59 \\
\text { anos (número) }\end{array}$ & $\begin{array}{l}1,074^{\star \star} \\
(0,018)\end{array}$ & $\begin{array}{l}1,080^{\star *} \\
(0,015)\end{array}$ & $\begin{array}{l}1,105^{\star \star} \\
(0,015)\end{array}$ & $\begin{array}{l}1,080 * \\
(0,033)\end{array}$ & $\begin{array}{l}1,050 \star \star \\
(0,017)\end{array}$ & $\begin{array}{l}1,124^{\star \star} \\
(0,018)\end{array}$ & $\begin{array}{l}1,081^{* *} \\
(0,013)\end{array}$ & $\begin{array}{l}1,142^{\star \star} \\
(0,018)\end{array}$ \\
\hline $\begin{array}{l}\text { Pessoas de } 60 \text { anos e } \\
\text { mais (número) }\end{array}$ & $\begin{array}{l}1,027 \\
(0,099)\end{array}$ & $\begin{array}{l}1,251^{\star \star} \\
(0,104)\end{array}$ & $\begin{array}{l}1,106 \\
(0,107)\end{array}$ & $\begin{array}{l}1,031 \\
(0,184)\end{array}$ & $\begin{array}{l}1,173+ \\
(0,105)\end{array}$ & $\begin{array}{l}1,352^{\star *} \\
(0,131)\end{array}$ & $\begin{array}{l}1,155^{*} \\
(0,081)\end{array}$ & $\begin{array}{l}1,275^{\text {** }} \\
(0,112)\end{array}$ \\
\hline \multicolumn{9}{|l|}{ Ciclo de vida no lote } \\
\hline $\begin{array}{l}\text { Tempo de residência } \\
\text { no lote (anos) }\end{array}$ & $\begin{array}{l}1,111^{\star \star} \\
(0,038)\end{array}$ & $\begin{array}{l}1,107 \\
(0,076)\end{array}$ & $\begin{array}{l}1,111^{\star *} \\
(0,038)\end{array}$ & $\begin{array}{l}1,107 \\
(0,076)\end{array}$ & $\begin{array}{l}1,017+ \\
(0,010)\end{array}$ & $\begin{array}{l}1,004 \\
(0,010)\end{array}$ & $\begin{array}{l}1,041^{\star *} \\
(0,012)\end{array}$ & $\begin{array}{l}1,037^{\star \star} \\
(0,013)\end{array}$ \\
\hline $\begin{array}{l}\text { Tempo de residência } \\
\text { no lote ao quadrado }\end{array}$ & $\begin{array}{l}\mathbf{0 , 9 4 7 * \star} \\
(0,017)\end{array}$ & $\begin{array}{l}0,933+ \\
(0,035)\end{array}$ & $\begin{array}{l}0,947^{* *} \\
(0,017)\end{array}$ & $\begin{array}{l}0,933+ \\
(0,035)\end{array}$ & $\begin{array}{l}1,000 \\
(0,003)\end{array}$ & $\begin{array}{l}1,000 \\
(0,003)\end{array}$ & $\begin{array}{l}1,043^{* \star} \\
(0,004)\end{array}$ & $\begin{array}{l}1,052 * \star \\
(0,004)\end{array}$ \\
\hline \multicolumn{9}{|l|}{$\begin{array}{l}\text { Variáveis de } \\
\text { controle }\end{array}$} \\
\hline $\begin{array}{l}\text { Distância até o centro } \\
\text { urbano }(\mathrm{km})\end{array}$ & $\begin{array}{l}0,974^{\star \star} \\
(0,004)\end{array}$ & $\begin{array}{l}0,989 * * \\
(0,003)\end{array}$ & $\begin{array}{l}0,994+ \\
(0,003)\end{array}$ & $\begin{array}{l}\mathbf{0 , 9 7 2 * \star} \\
(0,007)\end{array}$ & $\begin{array}{l}0,995 \\
(0,004)\end{array}$ & $\begin{array}{l}\mathbf{0 , 9 8 9 * *} \\
(0,003)\end{array}$ & $\begin{array}{l}0,997 \\
(0,003)\end{array}$ & $\begin{array}{l}0,989^{\star *} \\
(0,003)\end{array}$ \\
\hline $\begin{array}{l}\text { Renda agrícola } \\
\text { (\% da renda familiar) }\end{array}$ & $\begin{array}{l}1, \mathbf{0 1 2} * \\
(0,005)\end{array}$ & $\begin{array}{l}1,240 * \star \\
(0,100)\end{array}$ & $\begin{array}{l}1,016+ \\
(0,009)\end{array}$ & $\begin{array}{l}0,996 \\
(0,014)\end{array}$ & $\begin{array}{l}1,123 \\
(0,103)\end{array}$ & $\begin{array}{l}1,550 \star \star \\
(0,144)\end{array}$ & $\begin{array}{l}1,032 \\
(0,028)\end{array}$ & $\begin{array}{l}1,040 \\
(0,032)\end{array}$ \\
\hline $\begin{array}{l}\text { Renda familiar } \\
(\mathrm{Cz} \$ / \mathrm{R} \$)\end{array}$ & $\begin{array}{l}1,000 \\
(0,000)\end{array}$ & $\begin{array}{l}1,001^{\star *} \\
(0,000)\end{array}$ & $\begin{array}{l}1,000 \\
(0,000)\end{array}$ & $\begin{array}{l}1,000 \\
(0,000)\end{array}$ & $\begin{array}{l}1,001 * \star \\
(0,000)\end{array}$ & $\begin{array}{l}1,001^{\star \star} \\
(0,000)\end{array}$ & $\begin{array}{l}1,001^{\star \star} \\
(0,000)\end{array}$ & $\begin{array}{l}1,001^{\star *} \\
(0,000)\end{array}$ \\
\hline Tamanho do lote (ha) & 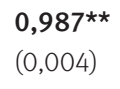 & $\begin{array}{l}\mathbf{0 , 9 8 6 * \star} \\
(0,003)\end{array}$ & $\begin{array}{l}0,980 \text { ** } \\
(0,004)\end{array}$ & $\begin{array}{l}0,993 \\
(0,007)\end{array}$ & 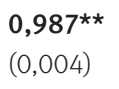 & $\begin{array}{l}\mathbf{0 , 9 8 1 * *} \\
(0,004)\end{array}$ & $\begin{array}{l}0,988^{* *} \\
(0,003)\end{array}$ & $\begin{array}{l}0,985^{\star *} \\
(0,004)\end{array}$ \\
\hline Constante & $\begin{array}{c}0,877 \\
(0,232)\end{array}$ & $\begin{array}{l}2,236^{\star \star} \\
(0,516)\end{array}$ & $\begin{array}{l}0,444^{\star \star} \\
(0,111)\end{array}$ & $\begin{array}{l}0,088^{\star *} \\
(0,041)\end{array}$ & $\begin{array}{l}1,172 \\
(0,309)\end{array}$ & $\begin{array}{l}0,825 \\
(0,223)\end{array}$ & $\begin{array}{l}0,352^{\star \star} \\
(0,073)\end{array}$ & $\begin{array}{l}0,190^{\star *} \\
(0,048)\end{array}$ \\
\hline Observações & 732 & 897 & 732 & 897 & 732 & 897 & 732 & 897 \\
\hline
\end{tabular}

Fonte: Levantamento domiciliar realizado em Machadinho d'Oeste, RO - 1987, 1995. Elaboração dos autores. Nota: Erros-padrão robustos entre parênteses. ${ }^{*}$ p $<0,01,{ }^{*} p<0,05,+p<0,1$

O efeito da distância até o centro urbano mostrou-se negativo para todas as classes, o que já havia sido apontado pela Tabela 2. Esse efeito de distância é, em geral, justificado pelos modelos de bid-rent (NELSON, 2002), em que terras marginas teriam um menor valor devido ao maior custo de transporte para escoamento de produtos, reduzindo sua 
atratividade (CATTANEO et al., 2001). Os efeitos do percentual da renda familiar derivado da agricultura apresentaram sinais curiosos, mas compatíveis com a estrutura de uso do solo na região. 0 efeito positivo sobre desmatamento e culturas anuais em 1995 (mas não significativo para usos comerciais) sugere que famílias mais pobres derivam uma importante parcela de sua renda da venda de culturais anuais. Barbieri et al. $(2013,2016)$ mostram que esse tipo de atividade é comum em domicílios mais pobres, onde a produção de culturas anuais (como mandioca, arroz e feijão) é utilizada tanto para subsistência quanto para venda do excedente nos mercados locais. É possível que o uso comercial neste estágio ainda estivesse em expansão, resultando em pouco impacto na renda familiar. Guedes et al. (2017), por exemplo, mostram que investimento em culturas perenes pode demorar alguns anos para que o domicílio tenha um benefício líquido. ${ }^{11}$

\section{Considerações finais}

O desmatamento continua sendo a principal questão ambiental da Amazônia. Devido à sua relevância e atualidade, esforços científicos para identificar suas causas e projetos de monitoramento para acompanhar sua evolução espaço-temporal têm produzido uma literatura vasta, tanto técnica quanto científica. Muitos estudos das décadas de 1980 e 1990 atribuíram as elevadas taxas de desmatamento à expansão populacional observada na região e às escolhas feitas pelos pequenos agricultores - o chamado "ciclo do colono pioneiro" (RINDFUSS et al., 2007). Inspirados nos modelos Ipat, tais estudos procuraram essas associações em escalas espaciais agregadas, incorrendo frequentemente em evidências conflituosas, ora atribuindo a responsabilidade às estratégias não sustentáveis da população local, ora informando efeitos não significativos da dinâmica demográfica regional (CORTES; D’ANTONA, 2014).

Com a evolução da fronteira e a crescente integração desta com os mercados, novas formas de uso do solo e estruturas fundiárias se desenvolveram. Fronteiras tradicionalmente colonizadas por pequenos agricultores, como Santarém, no Pará, e Lucas do Rio Verde, no Mato Grosso, passaram a conviver com a organização agrícola sob os auspícios do agronegócio (VANWEY et al., 2013; RICHARDS; VANWEY, 2015). Essa complexidade na organização espacial do uso do solo na Amazônia dificulta atribuir causas locais a processos heterogêneos analisados regionalmente. Mais do que nunca, análises bottom-up são essenciais para se entender os mecanismos de causalidade entre população e dinâmica de uso e cobertura do solo, bem como as escolhas dos agentes rurais e suas consequências ambientais de curto, médio e longo prazos (BARBIERI, 2007; CORTES; D’ANTONA, 2014).

\footnotetext{
${ }^{11}$ É importante destacar que os indicadores de integração com o mercado são endógenos à dinâmica de uso e cobertura do solo nos modelos estimados neste trabalho. No limite, a própria distância é endógena caso o retorno marginal da terra se altere com o desmatamento (NELSON, 2002). 0 viés de atenuação nos efeitos, comum em situações de endogeneidade por simultaneidade, pode ser a razão de efeitos muito pequenos verificados nos resultados apresentados na Tabela 3.
} 
Vários arcabouços conceituais foram propostos nos últimos anos para tentar explicar essa dinâmica em fronteiras agrícolas, incorporando elementos de organização espacial e viária (PFAFF et al., 2009), estratégias de sobrevivência (DE SHERBININ et al., 2008), retorno de capitais (WALKER, 2003; CALDAS et al., 2007; VANWEY et al., 2012a) e dinâmica demográfica local (MCCRACKEN et al., 1999; GUEDES et al., 2017). Nos últimos 20 anos observou-se também um número crescente de pesquisas locais, domiciliares e espacialmente explícitas, com rica informação longitudinal sobre características sociodemográficas dos agricultores e de uso e cobertura do solo em áreas de assentamento agrícola da Amazônia brasileira (VANWEY et al., 2007, 2013; RICHARDS; VANWEY, 2015), peruana (CHAVEZ et al., 2014) e equatoriana (BARBIERI et al., 2005; PAN; CARR, 2016). Esses estudos produziram evidências contraditórias dos efeitos demográficos sobre a evolução do desmatamento e de seus usos.

Essa ambiguidade empírica contrasta com as relações causais estabelecidas nos arcabouços conceituais, os quais sugerem um efeito não linear e decrescente do ciclo de vida dos domicílios agrícolas sobre as decisões de uso do solo ao longo do desenvolvimento das fronteiras (CALDAS et al., 2007). Advogamos que isso advém da limitação dos dados em analisar essa relação na escala temporal adequada. É exatamente na implantação das fronteiras agrícolas que a associação entre dinâmica demográfica e ambiental é mais forte e evidente (VANWEY et al., 2007; MCCRAKEN et al., 1999), especialmente para o desmatamento (GUEDES et al., 2017).

Este artigo analisou como mudanças no ciclo de vida domiciliar e no ciclo do lote influenciam a demanda por terra (desmatamento) e a dinâmica do uso do solo entre pequenos agricultores, a partir do estudo de caso do Projeto de Assentamento Machadinho d'Oeste em Rondônia. Diferentemente de vários estudos que fizeram esse tipo de análise em fronteiras já consolidadas (BARBIERI et al., 2005; DE SHERBININ et al., 2008; GRAY et al., 2008; VANWEY et al., 2007; LUDEWIGS et al., 2009; CABRERA et al., 2012; SANTOS et al., 2012; GUEDES et al., 2017; ZINDA; ZHANG, 2017), o presente trabalho testou essas relações desde o início do projeto de assentamento, utilizando dados sobre os assentados a partir do seu momento de chegada à fronteira.

Observou-se que a relação entre composição demográfica domiciliar e uso do solo é complexa, embora significativa. A idade do proprietário mostrou-se negativamente associada à proporção desmatada do lote, sugerindo que a experiência agrícola do agricultor reduz a necessidade de extensificação. A oferta de trabalho familiar, por outro lado, mostrou-se positivamente relacionada com o desmatamento e as culturas anuais, especialmente entre os domicílios com idosos, sugerindo a predominância do cenário empty nest (PERZ, 2001). Observou-se também um efeito não linear para o ciclo no lote, em que o desmatamento é maior nos domicílios com menos tempo na fronteira e diminui entre os domicílios estabelecidos. Esse efeito, consistente ao longo do tempo e resistente à renovação fundiária, parece condizer com a hipótese de learning-by-doing (capital específico da terra), também sugerido e observado em outros estudos (GUEDES et al., 2017; BARBIERI et al., 2005; BRONDIZIO et al., 2002). 
Verificaram-se também indícios de rápida integração com os mercados locais. A proporção da renda derivada da agricultura (uma proxy para agricultura comercial) mostrou-se positivamente relacionada com a proporção desmatada do lote. A distância até o centro urbano de Machadinho, por seu turno, parece reduzir a pressão por terras marginais. Esse último efeito é difícil de ser definitivamente explicado com os dados utilizados neste estudo, embora a justificativa dada pelos modelos de bid-rent (NELSON, 2002) possam lançar alguma luz. Nesses modelos, as terras marginas possuem menor valor devido ao elevado custo de transporte para escoamento da produção, diminuindo sua atratividade comercial (CATTANEO et al., 2001).

Este estudo encontrou efeitos consistentes com os arcabouços propostos por Summers (2008), VanWey et al. (2012a) e Guedes et al. (2017). O efeito do ciclo de vida e no lote parecem se alimentar nos estágios iniciais da fronteira. Oferta de trabalho familiar e experiência agrícola são importantes dinamizadores da cobertura florestal nesses estágios. $\mathrm{Na}$ medida em que a fronteira se integra com o mercado, o ciclo no lote parece perder importância sobre o desmatamento. Guedes et al. (2017), Brondizio et al. (2002) e Walker et al. (2002) mostram, por exemplo, que esse tipo de ciclo é mais determinante para os sistemas comerciais de uso do solo, embora em fronteiras mais mercantilizadas o efeito seja quase completamente substituído pelas forças de mercado (MONTE-MÓR, 2004; SUMMERS, 2008). Em conjunto, os achados sugerem uma estratégia domiciliar que responde a diferenças de incentivos e retornos dos capitais disponíveis aos proprietários, os quais evoluem ao longo do desenvolvimento da fronteira, como sugerido por VanWey et al. (2012a).

Espera-se que este artigo represente uma importante contribuição à literatura sobre dinâmica populacional e ambiente na Amazônia, particularmente pelo fato de utilizar dados locais, espacialmente explícitos, e que incorporam a escala temporal mais apropriada para as análises pretendidas neste estudo. Entretanto, várias limitações persistem. Primeiro, a análise empreendida não se baseia no acompanhamento longitudinal dos entrevistados; por essa razão, potenciais efeitos de atenuação ocasionados por relações simultâneas não podem ser descartados. ${ }^{12}$ Segundo, os estágios avançados de desenvolvimento da fronteira não foram analisados. Essa escolha do período estudado justifica-se pelo tipo de hipótese testada. Conforme discutido anteriormente, o efeito desses ciclos é predominante apenas em estágios iniciais, sendo gradualmente substituído por fatores estritamente exógenos ao domicílio, como o grau de integração das fronteiras com os mercados e as instituições endógenas à fronteira (redes migratórias, associações técnicas e instituições de crédito subsidiado e a dinâmica da estrutura fundiária liderada pela intensificação tecnológica e capitalização produtiva, como no sistema de agronegócio).

A despeito dessas limitações, o presente estudo usa um banco de dados único que auxilia a compreender padrões demográficos recorrentes em fronteiras agrícolas que

\footnotetext{
12 A despeito da reconhecida relação simultânea e conjunta entre composição demográfica e uso do solo (PAN; CARR, 2015), VanWey et al. (2007) observaram um efeito significativo da estrutura domiciliar, mesmo após expurgar os efeitos da dinâmica temporal.
} 
compõem o bioma Amazônico, podendo informar futuras propostas de colonização, assim como fundamentar parâmetros para outros trabalhos que adotem modelagens de simulação para testar a dinâmica da cobertura florestal e sua trajetória futura na região, como no estudo de Carvalho et al. (2016).

\section{Referências}

ALDRICH, S. P.; et al. Land-cover and land-use change in the Brazilian Amazon: smallholders, ranchers, and frontier stratification. Economic Geography, Worcester, v. 82, n. 3, p. 265-288, 2006.

AMARAL, S. et al. Riverine communities as socio-spatial units of the urban process in Amazon: a typology for the lower Tapajós River (State of Pará, Brazil). Revista Brasileira de Estudos de População, v. 30, n. 2, p. 367-399, 2013.

BARBIERI, A. F.; BILSBORROW, R. E.; PAN, W. K. Farm household lifecycles and land use in the Ecuadorian Amazon. Population and Environment, New York, v. 27, n. 1, p. 1-27, Sep. 2005.

BARBIERI, A. F.; CARR, D. L.; BILSBORROW, R. E. Migration within the frontier: the second generation colonization in the Ecuadorian Amazon. Population Research and Policy Review, v. 28, n.3, p. 291-320, 2009.

BARBIERI, A. F.; GUEDES, G. R.; ANTIGO, M. Demographic dynamics, livelihoods and land use: a twenty five years longitudinal study for the Brazilian Amazon. In: XXVII IUSSP INTERNATIONAL POPULATION CONFERENCE. Annals... Busan, South Korea, 2013.

BARBIERI, A. F.; SANTOS, R. O.; GUEDES, G. R. The migration, environment and development nexus in the frontier: a review of the literature based on empirical evidences from the Brazilian Amazon. In: DETERMINANTS OF INTERNATIONAL MIGRATION CONFERENCE. Oxford: Demig, 2014.

BARBIERI, A. F. Mobilidade populacional, meio ambiente e uso da terra em áreas de fronteira: uma abordagem multiescalar. Revista Brasileira de Estudos de População, v. 24, n. 2, p. 225-246, 2007.

BHATTI, S. S. et al. Spatial interrelationships of quality of life with land use/land cover, demography and urbanization. Social Indicators Research, v. 132, n. 3, p. 1193-1216, 2017.

BRONDIZIO, E. S. Amazonian Caboclo and the açaí palm: forest farmers in the global market. New York: The New York Botanical Garden Press, 2008.

BRONDÍZIO, E. S.; MCCRACKEN, S. D.; MORAN, E. F.; SIQUEIRA, A. D.; NELSON, D. R.; RODRIGUEZ-PEDRAZA, C. The colonist footprint: toward a conceptual framework of land use and deforestation trajectories among small farmers in the Amazonian frontier. In: WOOD, C. H.; PORRO, R. (Ed.). Deforestation and land use in the Amazon. Gainsville, FL: University Press of Florida, 2002. p. 133-161.

BROWDER, J. O.; PEDLOWSKI, M. A.; SUMMERS, P. M. Land use patterns in the Brazilian Amazon: comparative farm-level evidence from Rondônia. Human Ecology, v. 32, n. 2, p. 197-224, 2004.

CABRERA, A. R. et al. Exploring demographic and lot effects in an ABM/LUCC of agriculture in the Brazilian Amazon. In: HEPPENSTALL, A. J.; CROOKS, A. T.; SEE, L.; BATTY, M. Agent-based models of geographical systems. Dordrecht, Netherlands: Springer, 2012. p. 663-676.

CALDAS, M. et al. Theorizing land cover and land use change: the peasant economy of Amazonian deforestation. Annals of the Association of American Geographers, v. 97, n. 1, p. 86-110, 2007. 
CARR, D. L.; SUTER, L.; BARBIERI, A. Population dynamics and tropical deforestation: state of the debate and conceptual challenges. Population and Environment, v. 27, n. 1, p. 89-113, 2005.

CARVALHO, T. S.; MAGALHÃES, A. S.; DOMINGUES, E. P. Desmatamento e a contribuição econômica da floresta na Amazônia. Estudos Econômicos (São Paulo), v. 46, n. 2, p. 499-531, 2016.

CASTRO, M. C.; SINGER, B. H. Agricultural settlement and soil quality in the Brazilian Amazon. Population and Environment, v. 34, n. 1, p. 22-43, 2012.

CATTANEO, A.; BARBIER, E. B.; BURGESS, J. C. Deforestation in the Brazilian Amazon: comparing the impacts of macroeconomic shocks, land tenure, and technological change. Land Economics, v. 77, n. 2, p. 219-240, 2001.

CEDEPLAR - Centro de Desenvolvimento e Planejamento Regional. Project Land Use, Climate and Infections in Western Amazonia (IAI/LUCIA).Research Report 2014. Belo Horizonte: Cedeplar/ UFMG, 2014.

CHÁVEZ, A. B.; BROADBENT, E. N.; ZAMBRANO, A. M. A. Smallholder policy adoption and land cover change in the southeastern Peruvian Amazon: a twenty-year perspective. Applied Geography, v. 53, p. 223-233, 2014.

CÔRTES, J. C.; D’ANTONA, Á. de O. Land use and land cover dynamics: prospects and challenges for demography. Revista Brasileira de Estudos de População, v. 31, n. 1, p. 191-210, 2014.

DA CRUZ, Z. Q.; SILVEIRA, J. C.; RIBEIRO, G. P. Ensaios de segmentação e classificação digital de uma unidade de conservação com imagens CBERS utilizando o sistema SPRING. Estudo de caso: Parque Nacional da Serra dos Órgãos (PARNASO). In: XIV SIMPÓSIO BRASILEIRO DE SENSORIAMENTO REMOTO. Anais... Natal: Inpe, 2009. p. 6853-6860.

DE SHERBININ, A.; VANWEY, L. K.; MCSWEENEY, K.; AGGARWL, R.; BARBIERI, A. F.; HENRY, S.; HUNTER, L. M.; TWINE, W.; WALKER, R. Rural household demographics, livelihoods and the environment. Global Environmental Change, n. 18, p. 38-53, 2008.

D’ANTONA, Á. de O.; VANWEY, L. K. Strategy for a sampling of the population and the land structure in studies on the use, covering and domestic units of the land. Revista Brasileira de Estudos de População, v. 24, n. 2, p. 263-275, 2007.

D’ANTONA, Á. de O.; VANWEY, L. K.; HAYASHI, C. M. Property size and land cover change in the Brazilian Amazon. Population and Environment, v. 27, n. 5-6, p. 373-396, 2006.

D’ANTONA, Á. de O.; CAK, A. D.; NASCIMENTO, T. T. do. Integrando desenhos e imagens de satélite no estudo de mudanças no uso e cobertura da terra. Ambient. soc., Campinas, v. 11, n. 1, p. 99-116, 2008.

D’ANTONA, Á. de O. et al. Polarização da estrutura fundiária e mudanças no uso e na cobertura da terra na Amazônia. Acta Amazonica, v. 41, n. 2, p. 223-232, 2011.

DIXSON, J. Farming systems and poverty: improving farmers' livelihoods in a changing world. Rome: FAO, 2001.

ELDER JR., G. H. Perspective on the life course. In: ELDER JR., G. H. G. (Ed.). Life course dynamics: trajectories and transitions, 1968-1980. Ithaca: Cornell University Press, 1985. p. 23-49.

FEARNSIDE, P. M. Deforestation in Brazilian Amazonia: the effect of population and land tenure. Ambio-Journal of Human Environment Research and Management, v. 22, n. 8, p. 537-545, 1993.

FERRARI, S. L. P.; CRIBARI-NETO, F. Beta regression for modelling rates and proportions. Journal of Applied Statistics, v. 31, n. 7, p. 799-815, 2004. 
GARDNER, T. A. et al. A social and ecological assessment of tropical land uses at multiple scales: the Sustainable Amazon Network. Phil. Trans. R. Soc. B, v. 368, n. 1619, 2013.

GRAY, C. L.; BILSBORROW, R. E.; BREMMER, J. L.; LU, F. Indigenous land use in the Ecuadorian Amazon: a cross-cultural and multilevel analysis. Human Ecology, v. 36, n. 1, p. 97-109, 2008.

GREENE, W. Accounting for excess zeros and sample selection in Poisson and Negative Binomial regression models. Working Paper EC-94-10, Stern School of Business, New York University, 1994.

GUEDES, G. R.; QUEIROZ, B. L.; BARBIERI, A. F.; VANWEY, L. K. Ciclo de vida domiciliar, ciclo do lote e mudança no uso da terra na Amazônia brasileira: revisão crítica da literatura. Revista Brasileira de Estudos de População, v. 28, n. 1, p. 231-240, 2011.

GUEDES, G. R.; VANWEY, L. K.; HULL, J.; ANTIGO, M.; BARBIERI, A. F. Poverty dynamics, ecological endowments, and land use among smallholders in the Brazilian Amazon. Social Science Research, v. 43, p. 74-91, 2014.

GUEDES, G. R.; QUEIROZ, B. L.; BARBIERI, A. F.; VANWEY, L. K. Ciclos de vida de la propiedad y del hogar, mercados y cambios en el uso y la cobertura de la tierra en la Amazonia brasileña. Notas de Población, v. 44, n. 104, 2017.

GUTIÉRREZ-VÉLEZ, V. H.; DEFRIES, R. Annual multi-resolution detection of land cover conversion to oil palm in the Peruvian Amazon. Remote Sensing of Environment, v. 129, p. 154-167, 2013.

HAMMEL, E. A. Chayanov revisited: a model for the economics of complex kin units. PNAS, v. 102, n. 19, p. 7043-7046, 2005.

HAYASHI, S.; SOUZA JR., C.; SALES, M.; VERÍSSIMO, A. Transparência florestal - Amazônia Legal. Belém, PA, Brazil. Imazon, 2011. Disponível em: 〈http://www.imazon.org.br/publicacoes/ transparencia-florestal/transparencia-florestal-amazonia-legal/boletim-transparencia-florestalda-amazonia-legal-marco-de-2011〉.

HOGAN, D. J.; MARANDOLA JR., E. Towards an interdisciplinary conceptualisation of vulnerability. Population, Space and Place, v. 11, n. 6, p. 455-471, 2005.

HUNTER, L. M.; NAWROTZKI, R. Migration and the environment. In: WHITE, M. J. (Ed.). International handbook of migration and population distribution. New York: Springer, 2016. p. 465-484.

LAURANCE, W. F. et al. Deforestation in Amazonia. Science, v. 304, n. 5674, p. 1109-1111, 2005. Predictors of deforestation in the Brazilian Amazon. Journal of Biogeography, v. 29, n. 5-6, p. 737-748, 2002.

LOMBARDI, T. T.; GUEDES, G. R.; BARBIERI, A. F. As estratégias de sobrevivência nos estudos sobre a fronteira na Amazônia: contribuições das perspectivas rurais e urbanas. Territórios e Fronteiras, v. 8, n. 2, p. 171-195, 2015.

LUDEWIGS, T.; D’ANTONA, A. O.; BRONDÍZIO, E. S.; HETRICK, S. Agrarian structure and land use change along the lifespan of three colonization areas in the Brazilian Amazon. World Development, v. 37, n. 8, p. 1348-1359, 2009.

MARTINE, G. O lugar do espaço na equação população/meio ambiente. Revista Brasileira de Estudos de População, v. 24, n. 2, p. 181-190, 2007.

MCCRACKEN, S. D. et al. Remote sensing and GIS at farm property level: demography and deforestation in the Brazilian Amazon. Photogrammetric Engineering and Remote Sensing, v. 65, n. 11, p. 1311-1320, 1999.

MENA, C. F. et al. Pressure on the Cuyabeno Wildlife Reserve: development and land use/cover change in the Northern Ecuadorian Amazon. World Development, v. 34, n. 10, p. 1831-1849, 2006. 
MIRANDA, E. E. de et al. Sustentabilidade agrícola na Amazônia - Machadinho d'Oeste. Campinas: Embrapa Monitoramento por Satélite, 2005. Disponível em: 〈http://www.machadinho.cnpm. embrapa.brı. Acesso em: 1 nov. 2015.

MONTE-MÓR, R. L. Modernities in the jungle: extended urbanization in the Brazilian Amazonia. 2004. 378 f. Tese (Doutorado) - University of California, Los Angeles (UCLA), Los Angeles, 2004.

MORAN, E. F. et al. Human strategies for coping with El Niño related drought in Amazônia. Climatic Change, v. 77, n. 3, p. 343-361, 2006.

MORTON, D. C. et al. Cropland expansion changes deforestation dynamics in the southern Brazilian Amazon. Proceedings of the National Academy of Sciences, v. 103, n. 39, p. 14637-14641, 2006.

NELSON, G. C. Introduction to the special issue on spatial analysis for agricultural economists. Agricultural Economics, v. 27, n. 3, p. 197-200, 2002.

NEPSTAD, D. C. et al. Interactions among Amazon land use, forests and climate: prospects for a near-term forest tipping point. Philosophical Transactions of the Royal Society B: Biological Sciences, v. 363, n. 1498, p. 1737-1746, 2008.

PAN, W. K. Y.; BILSBORROW, R. E. The use of a multilevel statistical model to analyze factors influencing land use: a study of the Ecuadorian Amazon. Global and Planetary Change, v. 47, n. 2, p. 232-252, 2005.

PAN, W. K.; CARR, D. L. Land use as a mediating factor of fertility in the Amazon. Population and Environment, v. 38, n. 1, p. 21-46, 2016.

PAN, W. K. Y. et al. Farm-level models of spatial patterns of land use and land cover dynamics in the Ecuadorian Amazon. Agriculture, Ecosystems \& Environment, v. 101, n. 2, p. 117-134, 2004.

PAN, W. et al. Forest clearing in the Ecuadorian Amazon: a study of patterns over space and time. Population Research and Policy Review, v. 26, n. 5-6, p. 635-659, 2007.

PASQUIS, R. et al. "Réforme agraire” en Amazonie: bilan et perspectives. Cahiers Agricultures, v. 14, n. 1, p. 35-39, 2005.

PERZ, S. G. Population growth and net migration in the Brazilian Legal Amazon, 1970-1996. In: WOOD, C. H.; PORRO, R. (Ed.). Deforestation and land use in the Amazon. Gainesville, FL: University Press of Florida, 2002. p. 107-129.

Household demographic factors as life cycle determinants of land use in the Amazon. Population Research and Policy Review, v. 20, n. 3, p. 159-186, 2001.

PERZ, S. G.; ARAMBURÚ, C.; BREMNER, J. Population, land use and deforestation in the Pan Amazon Basin: a comparison of Brazil, Bolivia, Colombia, Ecuador, Peru and Venezuela. Environment, Development and Sustainability, v. 7, n. 1, p. 23-49, 2005.

PERZ, S. G.; WALKER, R. T. Household life cycles and secondary forest cover among small farm colonists in the Amazon. World Development, v. 30, n. 6, p. 1009-1027, 2002.

PFAFF, A. S. P. What drives deforestation in the Brazilian Amazon? Evidence from satellite and socioeconomic data. Journal of Environmental Economics and Management, v. 37, n. 1, p. 2643, 1999.

PFAFF, A.; BARBIERI, A.; LUDEWIGS, T.; MERRY, F.; PERZ, S.; REIS, E. Road impacts in Brazilian Amazonia. In: KELLER, M., M.; BUSTAMENTE, J. G.; DIAS, P. (Ed.). Amazonia and global change. American Geophysical Union. 2009. p. 101-116.

RAAD, R. J.; GUEDES, G. R. Private transfer choices under uncertainty in human capital. Revista Brasileira de Economia, v. 69, n. 1, p. 105-124, 2015. 
RICHARDS, P.; VANWEY, L. Where deforestation leads to urbanization: how resource extraction is leading to urban growth in the Brazilian Amazon. Annals of the Association of American Geographers, v. 105, n. 4, p. 806-823, 2015.

RINDFUSS, R. R. et al. Frontier land use change: synthesis, challenges, and next steps. Annals of the Association of American Geographers, v. 97, n. 4, p. 739-754, 2007.

RODRIGUES, A. S. L. et al. Boom-and-bust development patterns across the Amazon deforestation frontier. Science, v. 324, n. 5933, p. 1435-1437, 2009.

SANTOS, M. A. dos et al. Dinâmica demográfica e uso da terra no cerrado brasileiro: reflexões a partir da experiência do PADAP. Revista de Economia e Sociologia Rural, v. 50, n. 2, p. 319-331, 2012.

SAWYER, D. Economic and social consequences of malaria in new colonization projects in Brazil. Social Science \& Medicine, v. 37, n. 9, p. 1131-1136, 1993.

SCHMINK, M.; WOOD, C. Conflitos sociais e formação da Amazônia. Tradução de Noemi Miyasaka Porro e Raimundo Moura. Belém: Ed. UFPA, 2012.

SIMMONS, C. S. et al. The Amazon land war in the south of Pará. Annals of the Association of American Geographers, v. 97, n. 3, p. 567-592, 2007.

SMITHSON, M.; VERKUILEN, J. A better lemon squeezer? Maximum-likelihood regression with beta-distributed dependent variables. Psychological Methods, v. 11, n. 1, p. 54, 2006.

SOARES-FILHO, B. S. et al. Modelling conservation in the Amazon basin. Nature, v. 440, n. 7083, p. 520-523, 2006.

SUMMERS, P. M. The post-frontier: land use and social change in the Brazilian Amazon (1992-2002). 2008. 249 f. Tese (Doutorado) - Environmental Design and Planning, Virginia Polytechnic Institute and State University, Blacksburg, Virginia, 2008.

THORNER, D.; KERBLAY, B.; SMITH, R. E. F. (Ed.). Chayanov on the theory of the peasant economy. Homewood, IL: Richard D. Irwin, 1986.

TURNER, F. J. The frontier in American history. New York: Holt, 1920.

TURNER II, B. L. Deforestation in the southern Yucatán peninsular region: an integrative approach. Forest Ecology and Management, v. 154, n. 3, p. 353-370, Dec. 2001.

VANWEY, L.; VITHAYATHIL, T. Off-farm work among rural households: a case study in the Brazilian Amazon. Rural Sociology, v. 78, n. 1, p. 29-50, 2013.

VANWEY, L. K.; D’ANTONA, Á. de O.; BRONDÍZIO, E. S. Household demographic change and land use/land cover change in the Brazilian Amazon. Population and Environment, v. 28, n. 3, p. 163-185, 2007.

VANWEY, L. K.; HULL, J. R.; GUEDES, G. R. Capitals and context: bridging health and livelihoods in smallholder frontiers. In: KING, B.; CREWS-MEYER, K. (Ed.). Ecologies and politics of health. New York: Routledge Press, 2012a.

VANWEY, L. K.; GUEDES, G. R.; D’ANTONA, A. O. Out-migration and land-use change in agricultural frontiers: insights from Altamira settlement project. Population and Environment, v. 34, n. 1, p. 44-68, 2012b.

VANWEY, L. K.; D’ANTONA, A. O.; BRONDIZIO, E. S. Household demographic change and land use/land cover change in the Brazilian Amazon. Population and Environment, v. 28, n. 3, p. 163-185, 2007. 
VANWEY, L. K. et al. Socioeconomic development and agricultural intensification in Mato Grosso. Philosophical Transactions of the Royal Society of London B: Biological Sciences, v. 368, n. 1619, p. 20120168, 2013.

WALKER, R. T. Theorizing land-cover and land-use change: the case of tropical deforestation. International Regional Science Review, v. 27, n. 3, p. 247-270, Jul. 2004.

Mapping process to pattern in the landscape change of the Amazonian Frontier. Annals of the Association of American Geographers, v. 93, n. 2, p. 376-398, 2003.

WALKER, R. T. et al. Land use and land cover change in forest frontiers: the role of household life cycles. International Regional Science Review, v. 25, n. 2, p. 169-199, 2002.

WALKER, R.; MORAN, E.; ANSELIN, L. Deforestation and cattle ranching in the Brazilian Amazon: external capital and household processes. World Development, v. 28, n. 4, p. 683-699, 2000.

WOOD, C. H.; SKOLE, D. Linking satellite, census, and survey data to study deforestation in the Brazilian Amazon. In: NATIONAL RESEARCH COUNCIL. People and pixels: linking remote sensing and social science. Washington, DC: The National Academies Press, 1998. p. 70-93.

ZINDA, J.; ZHANG, Z. Land tenure legacies, household life cycles, and livelihood strategies in upland China. Rural Sociology, 2017.

\section{Sobre os autores}

Gilvan Ramalho Guedes é doutor em Demografia pelo Centro de Desenvolvimento e Planejamento Regional, Universidade Federal de Minas Gerais (Cedeplar/UFMG). Professor do Departamento de Demografia da UFMG.

Alisson Barbieri é doutor em Planejamento Regional e Urbano, University of North Carolina Chapel Hill, EUA. Professor do Departamento de Demografia da Universidade Federal de Minas Gerais (UFMG), pesquisador do Centro de Desenvolvimento e Planejamento Regional (Cedeplar) da UFMG.

Reinaldo Santos é doutorando em Demografia na Universidade Federal de Minas Gerais (UFMG). Vanessa Ferreira é doutoranda em Demografia na Universidade Federal de Minas Gerais (UFMG).

\section{Endereço para correspondência}

Gilvan Ramalho Guedes

Cedeplar - Centro de Desenvolvimento e Planejamento Regional

Faculdade de Ciências Econômicas - $3^{\circ}$ andar

Av. Antônio Carlos, 6627 - Pampulha

31270-901 - Belo Horizonte-MG, Brasil

Alisson Barbieri

Cedeplar - Centro de Desenvolvimento e Planejamento Regional

Faculdade de Ciências Econômicas - 3ํandar

Av. Antônio Carlos, 6627 - Pampulha

31270-901 - Belo Horizonte-MG, Brasil

Reinaldo Santos

Cedeplar - Centro de Desenvolvimento e Planejamento Regional

Faculdade de Ciências Econômicas - 3ํandar

Av. Antônio Carlos, 6627 - Pampulha

31270-901 - Belo Horizonte-MG, Brasil 


\author{
Vanessa Ferreira \\ Cedeplar - Centro de Desenvolvimento e Planejamento Regional \\ Faculdade de Ciências Econômicas - 3ํandar \\ Av. Antônio Carlos, 6627 - Pampulha \\ 31270-901 - Belo Horizonte-MG, Brasil
}

\begin{abstract}
Household demographic composition and land use dynamics in Machadinho d'Oeste, Rondônia: evidence from the frontier onset

Previous studies have found evidence of the importance of changes in household composition to explain land use choices in agricultural frontiers. Most of these studies, however, analyze these dynamics at later stages of the frontier development, rendering mixed evidence on the role of population drivers. This study examines the effects of household demographic composition (household life cycle) and time on property (property life cycle) on land use dynamics in small farms at Machadinho d'Oeste, Rondônia. Based on a unique dataset covering the agricultural frontier since its onset, the study analyzes these effects when their association with land cover dynamics is most likely. Data collected in 1987 and 1995 for a census survey regarding settlers on the original settlement area was used for the study. The relationship between cycles and types of land use was analyzed and modelled by means of Beta and Dirichlet regression models. A consistent relation between family labor supply and deforested stock was observed with regards to rural property. Time on the property was also associated with deforestation, although its non-linear effect suggests experimentation with the local biophysical environment. The effect of the life cycle and of the lot are self-determined in the initial stages of frontier development, indicating the relevance of the demographic dynamics of households for land use choices in agricultural frontiers.
\end{abstract}

Keywords: Machadinho d'Oeste. Brazilian Amazon. Agricultural frontier. Household life cycle. Property life cycle. Deforestation.

\title{
Resumen
}

Composición demográfica domiciliaria y dinámica del uso del suelo en Machadinho d'Oeste, Rondônia: evidencias basadas en las etapas iniciales de la frontera

Varios estudios sugieren la importancia de los cambios en la composición demográfica domiciliaria sobre la demanda y el uso de la tierra en fronteras agrícolas. La mayoría de esos estudios analiza sin embargo esa relación en etapas más avanzadas del desarrollo de las fronteras, y han producido evidencias conflictivas sobre el papel de los determinantes poblacionales. Este artículo examina los efectos de la composición demográfica del hogar (ciclo de vida domiciliaria) y del tiempo en la propiedad (ciclo en el lote) sobre la dinámica del uso del suelo en pequeñas propiedades rurales en Machadinho d'Oeste, Rondônia. Para ello fueron utilizados datos censales sobre los colonos del proyecto de asentamiento original para los años 1987 y 1995. La relación entre los ciclos y los tipos de uso del suelo fue analizada por medio de modelos de regresión Beta y de Dirichlet. Se observó una relación consistente entre la oferta de trabajo familiar y el stock deforestado en el nivel de la propiedad rural. El tiempo en 
Guedes, G.R. et al. Composição demográfica domiciliar e dinâmica do uso do solo em Machadinho d’Oeste, Rondônia

la propiedad también aparece asociado a la deforestación, aunque su efecto no linear sugiera la experimentación con el ambiente biofísico local. Se sugiere que el efecto del ciclo de vida y en el lote se determina en las etapas iniciales de la frontera, indicando la importancia de los efectos de la composición demográfica sobre la dinámica del uso de la tierra.

Palabras clave: Machadinho d’Oeste. Amazonia brasileña. Frontera agrícola. Ciclo de vida del hogar. Ciclo de la propiedad. Deforestación.

Recebido para publicação em 10/06/2017 Aceito para publicação em 28/07/2017 
